\title{
La reforma del mercado de trabajo en España durante la crisis financiera internacional
}

\author{
The labor market reform in Spain during the international \\ financial crisis
}

ANTONIO OJEDA \& MIGUEL GUTIÉRREZ*

Resumen: La crisis surgida en 2008 ha provocado una acusada degradación del empleo en España y una legislación de emergencia en muy poco tiempo, que se analiza en el estudio.

Palabras clave: reforma laboral - mercado de trabajo - subvenciones al empleo - formación profesional - fondo de compensación individual contrato único - situación laboral - contrato en prácticas y para la formación desempleo juvenil - reducción de jornada de trabajo - trabajo a tiempo parcial - agencias de colocación - servicio público de empleo

Summary: The crisis emerged in 2008 has caused a marked degradation of employment in Spain and an emergency legislation in a very short time, which is analyzed in the study.

Keywords: labor reform - labor market - employment subsidies - professional training - individual compensation fund - unique contract - labor situation - contract in practices and training - youth unemployment - reduction of working day - part-time work - employment agencies - Public service of employment

\footnotetext{
CONTENIDO: I. LA DETERIORADA SITUACIÓN DEL MERCADO LABORAL EN ESPAÑA.- II. LA REDUCCIÓN DE LA JORNADA DE TRABAJO COMO INSTRUMENTO DE MANTENIMIENTO DEL EMPLEO FRENTE A LA CRISIS.III. LA INTERMEDIACIÓN LABORAL: SERVICIO PÚBLICO DE EMPLEO Y AGENCIAS DE COLOCACIÓN.- IV. MEDIDAS DE FOMENTO DEL EMPLEO JUVENIL: EL CONTRATO EN PRÁCTICAS Y EL CONTRATO PARA LA FORMACIÓN.- V. EL RÉGIMEN DE INCENTIVOS A LA CONTRATACIÓN COMO MEDIDA DE FOMENTO DE EMPLEO.- VI. EL FONDO ESPAÑOL DE CAPITALIZACIÓN INDIVIDUAL: UNA MEDIDA CONTROVERTIDA
}

\footnotetext{
* Antonio Ojeda es catedrático de Derecho del Trabajo de la Universidad de Sevilla y Doctor honoris causa por la Pontificia Universidad Católica del Perú. Presidente de la Asociación Española de Salud y Seguridad Social y del Instituto Europeo de Relaciones Industriales. Miguel Gutiérrez es doctor por la Universidad de Sevilla e investigador en el programa EcOGES (Estudio de políticas activas de empleo en Europa) y en el Grupo de Investigación de la Junta de Andalucía sobre Negociación Colectiva.
} 


\section{LA DETERIORADA SITUACIÓN DEL MERCADO LABORAL EN ESPAÑA}

La grave crisis económica por la que venimos atravesando a nivel internacional se ha visto agravada sobremanera en España, adquiriendo unas dimensiones aun más amplias que en el resto de países de nuestro entorno. Pudiendo deducirse de los datos macroeconómicos que ofrece nuestro país que la recuperación económica será aun más lenta que en otros país vecinos, tal y como se ha venido a exponer por diversos organismos nacionales e internacionales ${ }^{1}$.

A consecuencia del negativo panorama económico que viene a ofrecer nuestro país, la situación del mercado laboral español presenta una situación devastadora y ha convertido al mismo en el principal problema con el que se han de enfrentar las autoridades públicas españolas.

En este sentido, como es consabido, los datos más preocupantes son los referentes al desempleo que viene aumentando de forma importante, y porqué no decirlo, de forma alarmante desde hace más de tres años ${ }^{2}$, lo que ha colocado a España en la peor situación dentro de los países de la Unión Europea, puesto que con una tasa de desempleo por encima del $21 \%{ }^{3}$, llega a duplicar y triplicar la tasa de desempleo de los principales países europeos.

Dentro de nuestras fronteras, el desempleo ha afectado a todas las Comunidades Autónomas, oscilando la tasa de desempleo entre el $11,61 \%$ del País Vasco y el 29,68\% de Andalucía, la cual lidera un ascenso espectacular de su índice de desempleo, situándose por encima del millón de desempleados ${ }^{4}$.

Además, si acudimos no ya al criterio territorial sino al criterio subjetivo, se puede apreciar cómo si bien el desempleo ha aumentado de forma

1 En este sentido, en el Informe semestral de perspectivas emitido en mayo de 2010 por la Organización para la Cooperación y el Desarrollo Económico (OCDE), se contempla que la previsión para 2011 es de una subida del $\mathrm{PBI}$ español del $0,9 \%$, siendo la subida pronosticada para los países miembros de aquella de un 2,8\% y la media de los países de la Zona Euro de un 1,8\% de crecimiento (ver Organización para la Cooperación y el Desarrollo Económico(www.oecd.org). Sitio web oficial de la OCDE; contiene información sobre la organización y enlaces de interés).

2 Téngase en cuenta que la cifra de desempleados no llegaba a los 1,8 millones de desempleados en el tercer trimestre de 2007, situándose la tasa de desempleo en torno al $8,5 \%$ (ver Anuario de estadísticas del Ministerio de Trabajo e Inmigración 2007, http://www.empleo.gob.es/es/estadisticas contenidos/anuario.htm. Sitio web oficial del Ministerio de Trabajo de España.

3 En el primer trimestre de 2011. España presenta una tasa de desempleo del $21,29 \%$ y se sitúa en 4.910.200. En los últimos 12 meses la cifra total de desempleados ha aumentado en 297.400. Datos ofrecidos por la Encuesta de Población Activa (EPA) en el primer trimestre de 2011 (ver Instituto Nacional de Estadística (www.ine.es). Sitio web oficial del instituto; contiene los resultados de todas las encuestas realizadas. En adelante, EPA). A este respecto, ver el informe del Instituto Internacional de Estudios Laborales(IIEL) de la Organización Internacional del Trabajo (OIT), Estudios sobre el crecimiento con equidad. España: empleo de calidad para una nueva economía, donde se destaca que la tasa de desempleo se sitúa 13 puntos porcentuales por encima de la de 2008 (OIT (IIEL). Estudios sobre el crecimiento con equidad. España: empleo de calidad para una nueva economía. Ginebra: IIEL, 2011, p. 2. Disponible en línea en el sitio web oficial de la OIT (http://www.ilo.org/public, spanish/bureau/inst/download/country_ss.pdif)).

4 Datos ofrecidos por la EPA en el primer trimestre de 2011. 
significativa en todos los colectivos de desempleados, son los jóvenes, y dentro de ellos los varones, los que están sufriendo de manera más virulenta la crisis del empleo 5 . A este respecto, la tasa de desempleo juvenil española se sitúa por encima del $40 \%{ }^{6}$, lo que ha colocado a nuestro país a la cabeza de Europa en lo que a este extremo se refiere, convirtiéndose este en uno de los mayores problemas que han de afrontar los dirigentes españoles, lo cual ha provocado que se pongan en marcha una serie de medidas e iniciativas, con el fin de tratar de atajar esta grave situación que presenta este colectivo, tal y como tendremos la ocasión de examinar posteriormente.

Así pues, en este contexto que presenta el mercado laboral español marcado por la grave situación del desempleo, queremos resaltar que hasta el momento las previsiones de recuperación del empleo en España no son demasiado optimistas, a tenor de las informaciones vertidas por algunos organismos internacionales como es el caso de la OCDE, quien sostiene que aunque el nivel medio de desempleo empiece a bajar en 2012, lo hará de forma muy moderada y se quedará de media en el $19,3 \%$, y no en el $17,4 \%$ que había calculado en su informe precedente. De hecho, las previsiones más a largo plazo de la OCDE estiman que la tasa de paro de España se situará en el 14,5\% en el cuarto trimestre de 2015 y solo se situará en un nivel similar al anterior a la crisis en 2026, cuando la tasa de desempleo se situará en el 8,9\%?.

Por otro lado, también debe destacarse, con relación al mercado laboral español, en consonancia con los datos de desempleo, la importante caída en la cifra de personas ocupadas, la cual se sitúa en 18.151 .700 personas en el primer trimestre de 2011, lo que supone una tasa de actividad del $59,88 \%$, lo que implica una disminución de aquella con respecto al segundo trimestre de 2010, donde la misma se situó en el 60,11\%, lo que suponía un total de 18.476 .900 personas ocupadas, esto es, 325.200 personas más ocupadas ${ }^{8}$. En este sentido, por Comunidades Autónomas la tasa de actividad fluctúa entre el 51,43\% del Principado de Asturias y el 64,24\% de la Comunidad de Madrid9.

Al margen de estos datos, otro aspecto a tener en cuenta, en lo que a la situación del mercado de trabajo español se refiere, es que la temporalidad tampoco arroja unos mejores resultados, ya que se puede afirmar que se ha mantenido estable, desde los años ochenta, en sus

5 En este sentido, se pronuncian, entre otros, MORALES ORTEGA, José Manuel. «El régimen de incentivos a la contratación tras la Ley 35/2010 de medidas urgentes para la reforma del mercado de trabajo». Temas Laborales, 107 (2010), pp. 375-405, p. 377.

6 Datos ofrecidos por Eurostat (www.epp.eurostat.ec.europa.eu), base de datos estadísticos de la Comisión Europea, para el año 2010.

7 Informe semestral de perspectivas emitido en mayo de 2011 por la OCDE (www.oecd.org).

8 Datos ofrecidos por la EPA.

9 Datos ofrecidos por la EPA.

LA REFORMA

DEL MERCADO

DETRABAJO EN

ESPAÑA DURANTE

LA CRISIS

FINANCIERA

INTERNACIONAL

THE LABOR

MARKET REFORM

IN SPAIN

DURING THE

INTERNATIONAL

FINANCIAL CRISIS 
altísimos índices, próximos al $25 \%{ }^{10}$, convirtiéndose de esta forma en un mal endémico de nuestro mercado de trabajo y colocando a España a la cabeza de Europa en lo que a este extremo se refiere. Este dato contrasta, por el contrario, con el empleo a tiempo parcial en nuestro país, el cual sigue siendo poco frecuente en nuestro mercado laboral en comparación con otras economías avanzadas. Tal es así, que este se cifraba en torno al $11,8 \%$ en 2009 , cuando la media de la OCDE para ese año era del $16,2 \%{ }^{11}$.

Por tanto, los anteriores barómetros que hemos expuesto, sobre todo, con relación a la elevada tasa de desempleo y el elevado índice de temporalidad, vienen a determinar la delicada salud que posee nuestro mercado laboral en estos momentos, tal y como hemos venido anunciando. Ello ha provocado que las autoridades de nuestro país hayan emprendido una importante reforma laboral, sobre todo, a raíz de la aprobación de la ley 35/2010, de 17 de septiembre, de medidas urgentes para la reforma del mercado de trabajo, con el fin de poner en marcha aquellos instrumentos necesarios para tratar de revertir la grave situación por la que atraviesa nuestro mercado de trabajo, en especial, en materia de empleo. Si bien, dos rasgos podrían definir esta reforma, por un lado, la misma aparece de manara tardía, puesto que, tal y como ya advirtiera la Unión Europea en 2008, «la crisis sería más severa con aquellos países cuyos Gobiernos no hayan actuado para respaldar el empleo, sino que hayan seguido aplicando la misma política que en tiempos de situación económica normal ${ }^{12}$, tal cual parece haber ocurrido en España. Y, por otro lado, esta reforma no ha venido sino a realizar revisiones parciales de nuestra política de empleo, sin que se haya llevado a cabo una reforma unitaria o conjunta de la política de empleo, rediseñándose la $\mathrm{misma}^{13}$. Por lo que se viene afirmando que, realmente, la ansiada reforma en torno a la política de empleo sigue aún por realizar en España ${ }^{14}$.

Pese a todo, trataremos de analizar en las próximas páginas aquellas medidas que han sido introducidas en nuestro ordenamiento jurídico, especialmente a través de la ley 35/2010, en materia de política de empleo, con el fin de evitar un aumento en la destrucción de empleo y,

10 En el primer trimestre de 2011 la tasa de temporalidad se sitúa en el $24,77 \%$, según los datos ofrecidos por la EPA.

11 OIT (IIEL). Ob. cit., p. 14.

12 Esto se afirmó en el Dictamen del Comité Económico y Social Europeo sobre la «propuesta de Decisión del Consejo relativa a las orientaciones para la política de empleo de los Estados miembros", DOCE de 17 de noviembre de 2009.

13 A este respecto, Morales OrTEGA, José Manuel. Ob. cit., p. 379. En esta línea ver Morón Prieto, Ricardo. Medidas urgentes para la reforma del mercado laboral. Comentarios a la Ley 35/2010, de 17 de septiembre. Madrid: El Derecho, p. 8 y MONTOYA MELGAR, Alfredo. «Introducción: crisis económica y reforma laboral». En MONTOYA MELGAR, Alfedo \& CAVAS MARTínez, Faustino (dirs.).Comentario a la reforma laboral de 2010. Ley 35/2010, de 17 de septiembre, de medidas urgentes para la reforma del mercado de trabajo. Navarra: Aranzadi, 2011, p. 30.

14 No obstante, se viene destacando en el concierto internacional el importante paso dado por nuestro país con la reforma que se ha llevado a cabo del mercado de trabajo aprobada en 2010 . En este sentido ver OIT (IIEL). Ob. cit., p. 4. 
sobre todo, con el fin de fomentar la inserción de los desempleados en el mercado de trabajo ${ }^{15}$, con especial referencia al colectivo más afectado en estos momentos, tal cual es, como sabemos, el de los jóvenes.

\section{LA REDUCCIÓN DE LA JORNADA DETRABAJO COMO INSTRUMENTO DE MANTENIMIENTO DEL EMPLEO FRENTE A LA CRISIS}

Aun cuando esta posibilidad ya existía en la legislación laboral española con anterioridad a la reforma de $2010^{16}$, uno de los aspectos más novedosos de la reforma legal introducida en España, en lo que a la regulación del mercado de trabajo se refiere, a través de la ley 35/2010, de 17 de septiembre, de medidas urgentes para la reforma del mercado de trabajo, es, precisamente, el referido a la reducción de la jornada como mecanismo para permitir el mantenimiento del empleo durante las situaciones de crisis económicas, evitando el recurso a las extinciones contractuales por causas económicas. En este sentido, el empleo exitoso de esta medida en otros países, fundamentalmente, en Alemania, donde gracias a la misma el impacto de la crisis en el empleo ha sido menor, ha provocado que dicha medida constituya uno de los escasos puntos de encuentro entre la doctrina laboralista de nuestro país, las fuerzas políticas y los interlocutores sociales, en lo que a la reforma laboral se refiere $^{17}$.

Como punto de partida para el análisis de esta medida debemos tener presente que el objetivo de la misma es, por un lado, favorecer la flexibilidad, facilitando el ajuste de las empresas a las necesidades cambiantes del mercado y, al mismo tiempo, proporcionar al trabajador seguridad, tanto en la conservación de su puesto de trabajo como en el mantenimiento de su nivel de ingresos económicos por la protección dispensada por el sistema de protección por desempleo, tal y como veremos posteriormente ${ }^{18}$.

Así, en primer término, desde el punto de vista laboral se ha modificado el artículo 47 del Estatuto de los Trabajadores —en adelante ET — para incorporar expresamente, en su apartado segundo, que «la jornada de trabajo podrá reducirse por causas económicas, técnicas, organizativas

15 En este sentido, el preámbulo de la Ley 35/2010, viene a afirmar que «[...] recuperar la senda de la creación de empleo y reducir el desempleo constituye en estos momentos una exigencia unánime del conjunto de la sociedad y, en consecuencia, debe constituir el objetivo último, fundamental, de todas las políticas públicas".

16 En este sentido, ver Morón PRIETO, Ricardo. Ob. cit., p. 46 y VIDAL VIDAL, Joaquin. «Ley 35/2010, de 17 de septiembre, y las reducciones de jornada con derecho a desempleo parcial». La Ley. Publicación en línea, 7560 (2011), p. 1501.

17 FerRando García, Francisca. «La reducción del tiempo de trabajo (suspensión del contrato y reducción de la jornada) como instrumento de flexibilidad interna». En MONTOYA MELGAR, Alfedo \& CAVAS MARTíneZ, Faustino (dirs.). Ob. cit.,p. 231.

18 A este respecto, ver MORón PRIETO, Ricardo. Ob. cit., p. 46.

LA REFORMA

DEL MERCADO

DE TRABAJO EN

ESPAÑA DURANTE

LA CRISIS

FINANCIERA

INTERNACIONAL

THE LABOR

MARKET REFORM

IN SPAIN

DURING THE

INTERNATIONAL

FINANCIAL CRISIS 
o de producción con arreglo al procedimiento previsto en el apartado anterior. A estos efectos, se entenderá por reducción de jornada la disminución temporal de entre un 10 y un $70 \%$ de la jornada de trabajo computada sobre la base de una jornada diaria, semanal, mensual o anual. Durante el período de reducción de jornada no podrán realizarse horas extraordinarias salvo fuerza mayor».

A tenor de este artículo, el primer aspecto a resaltar en torno a esta medida de reducción de jornada es que no hay lugar a dudas que el cauce a seguir a fin de proceder a la reducción de la jornada por las causas anteriormente indicadas es el expediente de regulación de empleo con independencia del número de trabajadores afectados por la medida. Consecuentemente, para reducir la jornada de trabajo se debe abrir un período de consultas entre la empresa y los representantes de los trabajadores, con el objeto de concluir un expediente de regulación de empleo que deberá ser autorizado por resolución de la autoridad laboral y, en caso de que no se concluya ese acuerdo, deberá ser la autoridad laboral la que emita la resolución estimatoria o desestimatoria. Dicho procedimiento solo podrá ser iniciado por el empresario, no estando legitimados para ello los representantes de los trabajadores. A este respecto, la justificación de este procedimiento se encuentra en la necesidad de controlar de forma pública esta medida, teniendo en cuenta el coste público que comporta la misma, básicamente, derivado de las prestaciones por desempleo, tal y como posteriormente veremos ${ }^{19}$.

Otro aspecto a tener en cuenta con relación a esta medida es que aquella constituye, en todo caso, una medida provisional, conectada a la superación de una situación de carácter coyuntural de la actividad de la empresa ${ }^{20}$. Así pues, la propia naturaleza provisional de esta medida determina la necesidad de que quede sin efecto si, superada la situación de crisis, la empresa incrementa su actividad. A este respecto, debe tenerse en cuenta un aspecto importante, y es que el legislador, a pesar del carácter provisional del que goza esta medida, ha eludido la fijación de un límite temporal máximo a la reducción de jornada, tal y como existe en el modelo alemán. Si bien, esta cuestión podría quedar establecida en el período de consultas, toda vez que los representantes de los trabajadores estarían interesados en limitar su duración al número máximo de días de reposición de la prestación por desempleo, que luego

19 A este respecto, ver FeRRANDo García, Francisca. Ob. cit., p. 232; VIDAL VIDAL, Joaquin. Ob. cit., pp. 1502-1503, quien advierte que se ha previsto un procedimiento especial para aquellas empresas que carecen de representante legal de los trabajadores y que pueden someterse a expediente de regulación de empleo, aplicándose las previsiones establecidas por la reforma laboral de 2010 para los artículos 40 y 41 del ET, a los cuales nos remitimos. No obstante, para mayor abundamiento en relación a esta cuestión y algunas otras relacionadas con el expediente de regulación de empleo en el marco de la reducción de jornada, ver FERRADANS CARAMÉs, Carmen. «La reducción de la jornada de trabajo como mecanismo de reestructuración empresarial frente a la crisis de empleo». Temas Laborales, 107 (2010), pp. 227-264, pp. 250 y ss.

20 Sobre la naturaleza provisional de la medida, ver FerRAndo García, Francisca. Ob. cit., p. 235. Asimismo, ver FerRadans Caramés, Carmen. Ob. cit., pp. 247 y ss. 
analizaremos, y, a su vez, el empresario estaría interesado en alcanzar el acuerdo con los representantes de los trabajadores, pues del mismo dependerá la obtención de determinados incentivos, que posteriormente veremos ${ }^{21}$.

No obstante, sin duda una de las novedades más llamativas en esta materia consiste en el establecimiento de unos amplios márgenes para la disminución del tiempo de trabajo. Así, el artículo 47.2 del ET así como los preceptos (203 y 208) de la Ley General de la Seguridad Social - en adelante LGSS_, que regulan la protección por desempleo que después veremos, contemplan aquella posibilidad a un mínimo del $10 \mathrm{y}$ un máximo del $70 \%$ de la jornada ordinaria de trabajo, siempre que el salario sea objeto de análoga reducción.

En este extremo debemos detenernos brevemente, puesto que podemos observar aquí cierta disfunción entre la regulación que se lleva a cabo en la normativa laboral y en la normativa de Seguridad Social, al regularse en esta última el desempleo parcial en caso de reducción de jornada. Y es que en el primero de los casos, esto es, en el artículo 47.2 del ET, como sabemos, se hace referencia a los límites mínimo y máximo, sin distinción, a la reducción de la jornada ordinaria diaria, semanal, mensual y anual. Mientras que en el segundo caso, esto es, en el artículo 203.3 de la LGSS, se alude a los citados límites, únicamente, como requisitos para considerar la existencia de desempleo parcial, cuando la reducción de la jornada afecta a la disminución del trabajo diario. A este respecto, viene entendiendo la doctrina que como en tantas otras instituciones que vinculan la protección de Seguridad Social a las vicisitudes contractuales, la normativa laboral y de Seguridad Social han de ser interpretadas conjuntamente, exigencia que, en el caso que aquí se trata, determina la necesidad de concluir que los límites mínimo y máximo deberían venir referidos al computo diario de la jornada ordinaria, según precisa la normativa de Seguridad Social ${ }^{22}$.

En este ámbito de disminución del tiempo de trabajo, un tema que queremos reseñar en estos momentos es si la reducción de la jornada de trabajo puede afectar a los trabajadores a tiempo parcial. En este sentido, el artículo 47.2 del ET no prohíbe esta posibilidad, puesto que dicho precepto únicamente establece límites mínimos y máximos a la reducción de jornada. Desde luego parecería razonable interpretar el artículo 47.2 del ET por analogía con el artículo 21.1 del ET, en el que se establece que la jornada diaria, semanal, mensual o anual de referencia es la ordinaria, y así se desprende de una interpretación conjunta con el artículo 203.3 de la LGSS que expresamente alude, como sabemos, a la jornada ordinaria. Ahora bien, de lo anterior no cabe inferir una prohibición de la reducción de la jornada de los trabajadores a tiempo 
parcial. Así pues, un trabajador a tiempo parcial podría ver reducida su jornada en la medida en que la jornada resultante no quedara fuera de los límites establecidos para la reducción de jornada ${ }^{23}$.

Por otro lado, otro aspecto a destacar por lo que se refiere a la regulación de esta medida es el hecho de que la medida de reducción de jornada será aplicable cualquiera que sea el número de trabajadores de la empresa y el número de trabajadores afectados. Bajo nuestro punto de vista, este es un elemento importante que contempla la 35/2010, puesto que supone la inclusión en esta institución de las pequeñas y medianas empresas ${ }^{24}$, las cuales, sin duda, son las mayormente afectadas en este período de crisis económica por el que atraviesa nuestro país.

Asimismo, en otro orden de cosas, con relación a esta institución se debe tener en cuenta que el último inciso del artículo 47.2 del ET prohíbe la realización de horas extraordinarias durante el período de reducción de jornada, salvo fuerza mayor, puesto que si aquellas se realizasen, se entendería que esta medida no es necesaria ${ }^{25}$. No obstante, en este sentido, se viene suscitando la duda acerca de si la prohibición afecta, únicamente, a los trabajadores afectados por el expediente de regulación de empleo, o a todos los trabajadores de la empresa ${ }^{26}$.

En otro orden de cosas, queremos analizar, a continuación, la protección por desempleo que lleva aparejada este mecanismo de la jornada reducida, como instrumento destinado a otorgar seguridad al trabajador, al posibilitar el mantenimiento de su nivel de ingresos económicos mientras tenga lugar la disminución del tiempo de trabajo.

En este sentido, en materia de protección social, mediante la reforma introducida por la ley 35/2010 se ha venido a adaptar la regulación del desempleo para hacerla compatible con las reducciones de jornadas. Así, se ha modificado el artículo 208 de la LGSS para determinar que se está en situación legal de desempleo cuando se reduzca temporalmente la jornada diaria de trabajo, en virtud de expediente de regulación de empleo en los términos del artículo 203.3 de la LGSS. Por su parte, dicho precepto viene a establecer que existe desempleo parcial cuando el trabajador vea reducida temporalmente su jornada diaria ordinaria de trabajo entre un mínimo de un 10 y un máximo de un $70 \%$, siempre que el salario sea objeto de análoga reducción. Además, el precepto establece que se entiende por reducción temporal de la jornada diaria ordinaria aquella que se autorice por un período de regulación de empleo, sin que estén comprendidas las reducciones de jornadas definitivas o que se extiendan a todo el período que resta de la vigencia del contrato de trabajo. Asimismo, el artículo 208.1.3 de la LGSS en concordancia, 
igualmente, con la regulación laboral, a la que aludimos anteriormente, establece como condición esencial para obtener la prestación por desempleo que la reducción de jornada se autorice en virtud del expediente de regulación de empleo ${ }^{27}$. Por último, en relación con la protección social motivada por la reducción de jornada, se incorpora un nuevo apartado 5 al artículo 210 de la LGSS para determinar que, en el caso de desempleo parcial, la consunción de prestaciones generadas se producirá por horas y no por días, de manera que el porcentaje consumido sea equivalente al de reducción de jornada autorizada ${ }^{28}$.

Por último, queremos abordar el tema de los incentivos que se establecen en la ley 35/2010 en relación con la reducción de jornada. El objetivo de estos incentivos parece claro: de un lado, incentivar la opción empresarial por soluciones que entrañan la conservación de los puestos de trabajo y, de otro lado, vencer la reticencia de los representantes de los trabajadores a la adopción de un acuerdo en tal sentido, en el curso, como sabemos, del preceptivo expediente de regulación de empleo ${ }^{29}$.

En este sentido, podemos destacar entre los incentivos más importantes introducidos por la ley los siguientes ${ }^{30}$ :incremento de la bonificación de cuotas empresariales por contingencias comunes ${ }^{31}$. En este sentido, la ley contempla, entre otras medidas de apoyo a la reducción del tiempo de trabajo, una bonificación del $80 \%$ de las cuotas empresariales a la Seguridad Social por contingencias comunes cuando la empresa, en los procedimientos de regulación de empleo que haya concluido con acuerdo, incluya medidas para reducir los efectos de la regulación temporal de empleo entre los trabajadores afectados, tales como acciones formativas durante el período de reducción de jornada, cuyo objeto sea aumentar la polivalencia del trabajador o incrementar su empleabilidad, medidas de flexibilidad interna que favorezcan la conciliación, o cualquier otra medida alternativa o complementaria dirigida a favorecer el mantenimiento del empleo en la empresa.

27 En este sentido, el Tribunal Constitucional (TC) viene afirmando que la exclusión del derecho a prestaciones por desempleo parcial en los supuestos de reducción de jornada no autorizados en expediente de regulación de empleo, sino fruto de un acuerdo entre empresario y trabajador o impuesta a través del artículo 41 del ET, no comporta la vulneración del artículo 14 CE (ver sentencia del TC número 213/2005, de fecha 21 de julio o auto del TC número 350/2005, de fecha 27 de septiembre).

28 Sobre la protección por desempleo en caso de jornada reducida, ver MORÓN PRIETO, Ricardo. Ob. cit., p. 47; FerRando García, Francisca. Ob. cit., pp. 242-243; FerRadans CaramÉs, Carmen. Ob. cit., pp. 260-261 o GONZÁLEZ ORTEGA,Santiago. "Seguridad Social y reforma del mercado de trabajo». Temas Laborales, 107 (2010), pp. 407-439, pp. 411 y ss.

29 En torno a los objetivos de estos incentivos, ver FERRANDo GARCía, Francisca. Ob. cit.,FERRANDO GARCÍA, F.: "La reducción del tiempo de trabajo...", op. cit; p. 248.

30 Con relación a estos incentivos, ver MORÓN PRIETO, Ricardo. Ob. cit., pp. 47-48; VIDAL VIDAL, Joaquin. Ob. cit., p. 1502; GonZÁlez ORTEGA, Santiago. Ob. cit., pp. 414 y ss. y FERRANDO García, Francisca. Ob. cit., pp. 247 y ss.

31 La ley 27/2009, de fecha 30 de diciembre, de medidas urgentes para el mantenimiento y el fomento del empleo y la protección de las personas desempleadas, introdujo en su día la bonificación del $50 \%$ de las cuotas empresariales a la Seguridad Social por contingencias comunes, devengadas por los trabajadores en situación de suspensión de contrato o reducción temporal de jornada, autorizadas en expediente de regulación de empleo o tramitadas de conformidad con la ley concursal. 
Asimismo, se flexibilizan las condiciones de acceso a las bonificaciones al reducirse el requisito del compromiso de mantenimiento del empleo de un año a tan solo seis meses, cuando se trate de acuerdos concluidos con posterioridad a la entrada en vigor de la ley 35/2010.

Por otro lado, se establece en 180 días el límite máximo de derecho de reposición, en caso de que tras un período de consumo de prestaciones por desempleo por reducción de jornada en expediente de regulación de empleo autorizado, finalmente, se autorice la extinción del contrato en expediente de regulación de empleo o resolución judicial en procedimiento concursal.

Hasta aquí, los rasgos más destacados que vienen a configurar esta medida a raíz de la reforma laboral introducida en 2010 en nuestro país, de la misma se espera que contribuya a frenar la destrucción de empleo que viene teniendo lugar en nuestro país desde hace más de tres años, aun cuando, quizás, las estipulaciones acerca de esta medida lleguen algo tarde, puesto que ha sido masiva la pérdida de puestos de trabajo en los últimos tiempos en nuestro país, como sabemos. Por ello, los mayores esfuerzos quizás deban centrarse en estos momentos en poner en marcha aquellas medidas necesarias para recuperar los puestos de trabajo destruidos, esto es, para lograr la inserción de los desocupados en el mercado de trabajo, siendo este uno de los aspectos que consideramos clave en la política de empleo de nuestro país. Es por ello, por lo que analizaremos, a continuación, las medidas que se contemplan en la ley 35/2010, precisamente, con ese objetivo de fomentar la inserción y la contratación de los desempleados, y en especial, de los colectivos más afectados por el desempleo, destacando, sobremanera, la población juvenil.

\section{LA INTERMEDIACIÓN LABORAL: SERVICIO PÚBLICO DE EMPLEO Y AGENCIAS DE COLOCACIÓN}

En este sentido, ante la alta tasa de desempleo que presenta nuestro país, la cual se sitúa, como sabemos, por encima del $20 \%$, la reforma aprobada en España, a través de la ley 35/2010, viene a establecer como objetivo esencial de dicha reforma la contribución a la reducción del desempleo, contemplándose en esta ley entre las medidas destinadas a dicho fin una serie de disposiciones que pretenden la mejora de los mecanismos de intermediación laboral ${ }^{32}$.

Tales medidas, tal y como ahora veremos, se centran, básicamente, en: coadyuvar a la modernización de los Servicios Públicos de Empleo,

32 Fernández Collados, María Belén. «Servicio público de empleo y agencia de colocación». En CAVAS MARTínEZ, Faustino \& José LUJÁN ALCARAZ (coords.). Guía práctica de la reforma laboral de 2010. Murcia: Laborum, p. 223. En la misma línea, ver RodríGUEZ-PIÑERO Y BRAVo FERRER, Miguel. «El nuevo régimen de las agencias privadas de colocación». Relaciones Laborales, 3 (2011), pp. 1-14, p. 2. 
mejorando su eficiencia y eficacia en la intermediación laboral, permitir la colaboración público-privada, especialmente, a través de la regulación legal de la actividad de las agencias de colocación con ánimo de lucro e incluir en el concepto de intermediación laboral a las empresas de recolocación o outplacement.

Así, en primer término, por lo que se refiere a los servicios públicos de empleo, se viene advirtiendo en torno a los mismos la deficiente cooperación existente entre las instituciones que integran el Servicio Nacional de Empleo (SNE) y la escasez de los recursos de toda índole asignados a estas instituciones. No basta solo con preservar la centralidad de los Servicios Públicos de Empleo ni reconocer su carácter imprescindible para promover los cambios en el acceso al empleo. Tampoco es suficiente, conforme establece la disposición adicional decimoséptima de la ley 35/2010, afirmar que el Gobierno seguirá reforzando los servicios públicos de empleo mediante la mejora de sus recursos humanos, tecnológicos y organizativos y de la red de oficinas. Además de todo ello, resulta imprescindible que las declaraciones acerca de la existencia de una efectiva voluntad política de potenciar y perfeccionar tales servicios se acompañen de medidas eficaces, capaces de plasmar en el orden económico, organizativo y humano esa voluntad ${ }^{33}$. Esta parece ser la dirección hacia la que se encamina, con el objeto de tratar de modernizar aquellos servicios, mejorando de este modo la eficiencia de los mismos en el marco de la intermediación laboral, el artículo 13 de la ley 35/2010, que autoriza al Gobierno para aprobar, como ya lo hiciera en su momento la Disposición Adicional Primera del Real Decreto Ley 2/2009, de 6 de marzo, de Medidas Urgentes para el Mantenimiento y el Fomento del Empleo y la Protección de las Personas Desempleadas, una nueva prórroga, por dos años más, del Plan Extraordinario de medidas de orientación, formación profesional e inserción laboral ${ }^{34}$, referida, exclusivamente, a la medida consistente en la contratación de 1.500 orientadores para el reforzamiento de la red de oficinas de empleo ${ }^{35}$. Lo que viene a significar la posibilidad de otorgar una atención más personalizada y de realizar itinerarios individuales de inserción laboral para las personas desempleadas o expuestas a su exclusión del mercado laboral. Dicha medida es de aplicación en todo el territorio del Estado y su gestión se realizará por

33 A este respecto, ver VALDÉS DAL-RÉ, Fernando. «La reforma de la intermediación laboral». Relaciones Laborales, 21-22 (2010), pp. 129-157, p. 225.

34 En este sentido, debe tenerse en cuenta que el artículo 8 del Real Decreto ley 2/2008, de 21 de abril, de Medidas de Impulso a la Actividad Económica, autorizaba al Gobierno la aprobación, mediante Acuerdo de Consejo de Ministros, de un Plan Extraordinario de medidas de orientación, formación profesional e inserción laboral, destinado a incrementar la contratación laboral y el reforzamiento de la estabilidad profesional tanto de las personas desempleadas como de las expuestas a su exclusión del mercado laboral. Dicho Plan fue aprobado por Acuerdo de Consejo de Ministros de 18 de abril de 2008.

35 Sin embargo, a pesar de los esfuerzos por contratar más personal el número de beneficiarios por funcionario a cargo se aproxima a 450/1 en los servicios públicos de empleo españoles, tasa que se encuentra entre las más elevadas de los países europeos (ver OIT (IIEL). Ob. cit., p. 9). 
las Comunidades Autónomas con competencias estatutariamente asumidas en el ámbito del trabajo, el empleo y la formación y por el Servicio Público de Empleo estatal.

No obstante, a pesar de este intento por aumentar la eficiencia de los servicios públicos de empleo, el cual no parece que resulte ni mucho menos suficiente ${ }^{36}$, uno de los aspectos más importantes que se contemplan en este terreno, en esta ley 35/2010, de reforma del mercado de trabajo, es, sin duda, la admisión de la colaboración públicoprivada en la intermediación laboral, concediéndose un amplio margen de actuación a las agencias privadas de colocación, incluidas, ahora, (y ahí estriba una de las novedades más destacadas en esta materia) las de carácter lucrativo.

Así, por lo que se refiere a la temática de las agencias de colocación, la ley 35/2010 viene a modificar diversas disposiciones de la ley 56/2003, de 16 de diciembre, Ley de Empleo, estableciendo, en concreto, en el nuevo apartado 1 del artículo 21 bis de aquella ley que se entenderá por agencia de colocación aquellas entidades públicas o privadas, con o sin ánimo de lucro, que realicen actividades de intermediación laboral. Consistiendo esta, a tenor de lo dispuesto por el artículo 20 de la citada Ley de Empleo, en el conjunto de acciones que tienen por objeto poner en contacto las ofertas de trabajo con los trabajadores que buscan un empleo, para su colocación. Por tanto, la ley, como uno de sus cambios más significativos, elimina, tal y como ya apuntamos, la prohibición de las agencias de colocación con ánimo lucrativo, contemplando expresamente las mismas ${ }^{37}$.

Al margen del reconocimiento expreso de las agencias de colocación con fines lucrativos, debe tenerse en cuenta otro aspecto importante en torno a las agencias de colocación, y es que la Ley contempla la posibilidad de que estas puedan desarrollar actuaciones relacionadas con la búsqueda de empleo, entre las cuales se mencionan la orientación y formación profesional y la selección de persona ${ }^{38}$. Si bien, se consideran, en todo caso, estas actividades, secundarias y accesorias, pudiendo ser desarrolladas las mismas por entidades que no reúnen la condición de agencia de colocación. Además, en este terreno, debe resaltarse que la

36 En este sentido, Valdés advierte que la medida formulada en el artículo 13 de la ley resulta de una manifiesta deficiencia al hacerse en soledad (ver ob. cit., p. 225). Téngase, además, en cuenta que el gasto en España en el Servicio Público de Empleo, expresado como porcentaje del gasto en programas activos del mercado de trabajo, es inferior al $18 \%$, lo cual contrasta con países como Alemania que invierten más del 35\% (ver OIT (IIEL). Ob. cit., p. 9).

37 VALDÉs DAL-RÉ, Fernando. Ob. cit., p. 229; FERNÁNDEZ ColLADOS, María Belén. «La intermediación laboral en la reforma de 2010: servicio público de empleo, políticas de empleo y agencias de colocación». En Montoya Melgar, Alfedo \& Cavas MaRTínez, Faustino (dirs.). Ob. cit., pp. 378-379 y RodRíGUeZ-PINEERO Y BRAVo FERRER, Miguel. Ob. cit., p. 2.

38 FERnÁNDEZ Collados, María Belén. «La intermediación laboral en la reforma de 2010: servicio público de empleo, políticas de empleo y agencias de colocación», p. 380 o MORÓN PRIETO, Ricardo. Ob. cit., p. 58. 
expresión búsqueda de empleo debe entenderse de manera concordante con la norma que la inspira, esto es, el artículo 1.1.c del Convenio 181 de la OIT, por lo que quedan fuera del campo de aplicación de esta expresión las actuaciones destinadas a emplear trabajadores con el fin de ponerlos a disposición de una tercera persona, esto es, la empresa usuaria, que determine sus tareas y supervise la ejecución de aquellas. Así, las agencias de colocación no podrán actuar simultáneamente como Empresas de Trabajo Temporal ${ }^{39}$.

No obstante, debe tenerse presente que la Ley mantiene el carácter de servicio público de la intermediación laboral, puesto que, tal y como en seguida veremos, a las agencias de colocación se les va a exigir para el desarrollo de sus actividades de intermediación una autorización otorgada por el Servicio Público de Empleo, y, además, las mismas, tal y como veremos, podrán actuar bien como colaboradoras de los servicios públicos de empleo, bien de manera autónoma pero coordinada con los mismos.

Así, en primer término, por lo que se refiere a la autorización administrativa con la que deben contar dichas agencias para desempeñar su actividad, la Ley establece que el desempeño de las actividades de intermediación como agencias privadas queda condicionado, al igual que con el real decreto 735/1995, a la obtención de una autorización del Servicio Público de Empleo. Si bien, la regulación de dicha autorización se establece reglamentariamente, en concreto, a través del real decreto 1796/2010, de 30 de diciembre, por el que se regulan las agencias de colocación. Viniendo, únicamente, la ley a especificar que la autorización será única y válida en todo el territorio nacional, que el órgano administrativo competente para su concesión variará en función de que la agencia actúe en diferentes Comunidades Autónomas (Servicio Público de Empleo estatal) o en una única Comunidad Autónoma (órgano equivalente de la Comunidad Autónoma), y que el silencio administrativo determinará la desestimación de la solicitud. En este sentido, entre las puntualizaciones más destacadas que efectúa la norma reglamentaria, queremos destacar, en estos momentos, que dicha norma establece que, igualmente, deberán solicitar autorización las entidades que casen ofertas y demandas de empleo utilizando exclusivamente medios electrónicos, correspondiendo en este caso la autorización al Servicio Público de Empleo estatal. Asimismo, se prevén en el capítulo III de dicha norma reglamentaria los procedimientos de concesión, ampliación y extinción de la autorización ${ }^{40}$. Además, se dispone en la norma reglamentaria que la información relativa a las autorizaciones concedidas, así como las autorizaciones para la modificación del ámbito

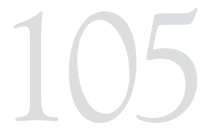

LA REFORMA

DEL MERCADO

DETRABAJO EN

ESPAÑA DURANTE

LA CRISIS

FINANCIERA

INTERNACIONAL

THE LABOR

MARKET REFORM

IN SPAIN

DURING THE

INTERNATIONAL

FINANCIAL CRISIS 
de actuación de las agencias de colocación, al objeto de que pueda ser conocida tanto por los servicios públicos de empleo como por la ciudadanía, quedará integrada en el espacio telemático común recogido en el artículo 6, dentro del sistema de información de los servicios públicos de empleo ${ }^{41}$.

En segundo término, uno de los extremos más relevantes, en lo que se refiere a la actuación de las agencias de colocación, es que aquellas, tal y como ya hemos esbozado, pueden actuar bien como entidades colaboradoras de los servicios públicos de empleo o bien pueden actuar de manera autónoma pero coordinada con dichos servicios.

En este sentido, en cuanto a la posibilidad de que dichas agencias actúen como entidades colaboradoras de los servicios públicos de empleo, la ley 35/2010 prevé que para poder realizar actividades de intermediación laboral como entidades colaboradoras de los servicios públicos de empleo, las agencias de colocación habrán de suscribir un convenio de colaboración, el cual regirá la relación de colaboración, concretando las particularidades de la misma ${ }^{42}$. En este sentido, el real decreto 1796/2010 contiene en su capítulo IV una regulación específica de las agencias de colocación como entidades colaboradoras de los servicios públicos de empleo. Así, dicha norma regula en su artículo 18 el objeto y el contenido de los convenios de colaboración, señalando el apartado 1 de dicho artículo que los convenios de colaboración tendrán por objeto la determinación de las actividades a desarrollar por las agencias de colocación que actúen como entidades colaboradoras de los servicios públicos de empleo, especificándose en el apartado 2 del mencionado artículo 18 el contenido mínimo de dicho convenio, el cual viene a ser el siguiente: ámbito de aplicación; duración, que podrá ser de uno a dos años; descripción de las acciones concretas a desarrollar; forma de financiación de las acciones objeto del convenio, con expresión de su vinculación a los resultados fijados; los medios materiales, humanos y económicos que empleará la agencia para acometer las acciones previstas; colectivos de demandantes destinatarios de los servicios; seguimiento y evaluación; definición de los sistemas de comunicación de la información; mecanismos de comunicación para dar cumplimiento a la obligación que tienen las agencias de colocación de comunicar las incidencias que se produzcan en relación con las obligaciones de

41 Sobre la autorización necesaria y su desarrollo reglamentario ver, FERNÁNDEZ CoLLADOS, María Belén. «La intermediación laboral en la reforma de 2010: servicio público de empleo, políticas de empleo y agencias de colocación», pp. 383-384. Y, especialmente, por lo que se refiere al desarrollo reglamentario de dicha autorización, ver RODRíGUEZ-PIÑERO Y BRAVO FERRER, Miguel. Ob. cit., pp., 8-9 y GARCíA NINET, José Ignacio \& SALIDO BANÚS, José Luis. «Intermediación laboral y agencias de colocación y de recolocación privadas. Comentario al RD 1796/2010, de 30 de diciembre». Revista General de Derecho del Trabajo y de la Seguridad Social. Publicación en línea, 24 (2011),pp. 17 y ss.

42 A este respecto, ver FERnÁNDEZ Collados, María Belén. «Servicio público de empleo y agencia de colocación». Ob. cit., p. 231; VALDÉs DAL-RÉ, Fernando. Ob. cit., p. 232 y GARCíA NinET, José Ignacio \& SALIDO BANúS, José Luis. Ob. cit., pp. 24 y ss. 
las personas trabajadoras y de las personas solicitantes y beneficiarias de prestaciones por desempleo ${ }^{43}$; los indicadores de eficacia definidos en función de la Disposición Adicional primera del real decreto 1796/201044; y el procedimiento y trámite para su modificación, así como la determinación de las causas extintivas. Por su parte, el artículo 19 del mencionado real decreto específica que los servicios públicos de empleo podrán establecer, en su correspondiente ámbito territorial, el procedimiento para suscribir convenios de colaboración con las agencias autorizadas para operar dentro del mismo. Este procedimiento podrá consistir en la concesión de subvenciones públicas, contratación administrativa o cualquier otra forma jurídica ajustada a la normativa estatal y autonómica ${ }^{45}$.

$\mathrm{Al}$ margen de las premisas anteriores, es importante resaltar en este terreno que los servicios prestados por las agencias de colocación como colaboradoras de los servicios públicos de empleo serán gratuitos tanto para el empresario como para los trabajadores, lo que implica que la suscripción de convenios se vincula a la aportación de recursos financieros públicos ${ }^{46}$. Así, la prohibición de percepción, por parte de esta modalidad de agencia de colocación, de contraprestación alguna ha de ser entendida en un doble sentido. De un lado, es general, afectando no solo a honorarios o tarifas, sino, también, a todo tipo de gastos sea cual fuere su causa. De otro lado, es universal, resultando aplicable a todo tipo de agente intermediador, incluidas las agencias de colocación sin ánimo de lucro ${ }^{47}$.

43 En estos casos, las obligaciones previstas en materia de seguridad social, esto es, participar en trabajos de colaboración social, renovar la demanda de empleo y comparecer, cuando haya sido previamente requerido, devolver el correspondiente justificante de haber cumplido en el lugar y fecha indicados para cubrir las ofertas de empleo, podrán ser exigidas o cumplidas ante las Entidades Gestoras, los servicios públicos de empleo o las agencias de colocación cuando desarrollen actividades en el ámbito de la colaboración con aquellos (artículo 231 de la LGSS en la redacción dada por la ley 35/2010). Ver MORÓN PRIETO, Ricardo. Ob. cit., p. 59.

44 Dicha disposición establece que los indicadores de eficacia de las agencias de colocación contemplarán, al menos, los siguientes aspectos: número de personas atendidas, número de personas atendidas perceptoras de prestaciones por desempleo, número de personas atendidas pertenecientes a colectivos con dificultades de inserción, número de ofertas y puestos de trabajo captados como resultado de su actividad de intermediación, número de ofertas y puestos de trabajo cubiertos con las personas atendidas como resultado de su actividad de intermediación, número de contratos de trabajo suscritos por las personas atendidas, número de contratos de trabajo indefinidos suscritos por las personas atendidas, y otros indicadores correspondientes al resto de servicios ofrecidos por la agencia. Dichos indicadores serán evaluados cada dos años a efectos de suscripción de posibles convenios de colaboración entre las agencias y los servicios públicos de empleo. En este sentido, Rodríguez-Piñero afirma que la previsión de unos indicadores de eficacia de las agencias de colocación a efectos de suscripción de posibles convenios de colaboración entre las agencias y los servicios públicos de empleo puede ser en el futuro un factor muy relevante para asegurar una selección objetiva de agencias de colaboración en régimen de libre concurrencia (ver RODRíGUEZPIÑERO Y BRAVo FERRER, Miguel. Ob. cit., p. 13).

45 Sobre el desarrollo reglamentario de las agencias de colocación como entidades colaboradoras de los servicios públicos, ver FERNÁNDEZ COLLADOS, María Belén. «La intermediación laboral en la reforma de 2010: servicio público de empleo, políticas de empleo y agencias de colocación», pp. 386-387 y RodrígueZ-PIÑERO Y BRAvo FERRER, Miguel. Ob. cit., pp. 11-13.

46 Ibídem, p. 13.

47 VALDÉS DAL-RÉ, Fernando. Ob. cit., p. 241. 
Por último, como colofón al tratamiento del papel de las agencias de colocación como entidades colaboradoras de los servicios públicos de empleo, queremos referirnos al tipo de agencias que pueden suscribir el correspondiente convenio de colaboración, obteniendo así la condición de agencia colaboradora. En este sentido, se ha venido entendiendo, aun cuando la ley 35/2010 no se pronuncia sobre este extremo, que las agencias privadas de colocación con ánimo de lucro no pueden aspirar a ser calificadas como agencias colaboradoras, siéndoles de aplicación la consideración de agencias autónomas, a las que seguidamente aludiremos. Pudiendo deducirse aquella conclusión de una interpretación conjunta del fin que ánima la constitución de este tipo de agencias y del tratamiento del régimen económico de la intermediación laboral enunciado en el artículo 22.4 de la Ley de Empleo, que, como hemos adelantado, establece la gratuidad de los servicios de intermediación laboral realizados por los servicios públicos de empleo o sus entidades colaboradoras ${ }^{48}$. No obstante, sobre la anterior cuestión se ha pronunciado el real decreto 1796/2010, restringiendo la actuación como colaboradoras de las agencias privadas con ánimo de lucro, al establecerse en el artículo $17 \mathrm{f}$ ) de la citada norma la exigencia de la acreditación de actividades realizadas con fondos no provenientes de los servicios públicos de empleo, que se configura como un requisito para poder suscribir convenios. Si bien, se viene advirtiendo que es esta una exigencia no contemplada en la ley y que es contraria a su espíritu y, posiblemente, discriminatoria y es producto de la desconfianza en el pasado hacia las agencias privadas de colocación ${ }^{49}$.

Por otro lado, tal y como ya hemos advertido, las agencias de colocación pueden actuar de manara autónoma pero coordinada con los servicios públicos de empleo, no teniendo ya que ser necesariamente colaboradoras del servicio público correspondiente. A partir de la ley 35/2010 las agencias de colocación aunque gestionen un servicio de carácter público y estén sometidas a una necesaria autorización realizan autónomamente una actividad económica, operando en el mercado ${ }^{50}$. Si bien, uno de los aspectos más destacados en este sentido es que la decisión del trabajador de acudir a los servicios de intermediación de estas agencias de colocación autónomas resulta económicamente neutra, pues no le puede ocasionar coste alguno. De tal forma que se establece como infracción muy grave exigir a los trabajadores coste o contraprestación por los servicios prestados. Sin embargo, si esa misma decisión de acudir a las agencias de colocación autónomas, al margen de

48 L. cit.

49 RodrígueZ-PIÑERo y Bravo FerReR, Miguel. Ob. cit., p. 12.

50 Sobre la posibilidad de actuar las agencias de colocación de manera autónoma, ver FERNÁNDEZ Collados, María Belén. «La intermediación laboral en la reforma de 2010: servicio público de empleo, políticas de empleo y agencias de colocación», p. 382; MoRón PRIETO, Ricardo. Ob. cit., p. 58 o Rodríguez-PIÑERO y Bravo FERRER, Miguel. Ob. cit., p. 5. 
que tengan o no ánimo lucrativo, es adoptada por el empresario, esta es onerosa para él, al cual estas entidades pueden requerir por los servicios prestados todo tipo de contraprestación, sin limitación cuantitativa ni objetiva. A este respecto, debe tenerse en cuenta que si la agencia de colocación privada no tiene fines lucrativos ello no significa la gratuidad de sus servicios, pues puede requerir la compensación de los gastos ocasionados por la intermediación ${ }^{51}$.

Por otro lado, una vez delimitadas las modalidades de agencias de colocación, ya sea como entidades colaboradoras de los servicios públicos ya sea como entidades autónomas pero coordinadas con estos, debe resaltarse el conjunto de obligaciones a las que la ley viene a someter a dichas agencias. Así, junto con las obligaciones genéricas que pueden derivarse de la regulación de las agencias de colocación desarrolladas reglamentariamente en el artículo 5 del real decreto 1796/2010 y las obligaciones específicas de las agencias de colocación colaboradoras de los servicios públicos de empleo determinadas reglamentariamente en el artículo 17 del real decreto 1796/2010, la ley establece una serie de obligaciones con la intención de controlar su actividad ${ }^{52}$ :

- Informar a los servicios públicos de empleo acerca de las demandas y las ofertas de empleo.

- Asegurar el respeto de la intimidad y dignidad de los trabajadores en el tratamiento de los datos, conforme a la normativa aplicable.

- Elaborar y ejecutar planes específicos para la colocación de los colectivos prioritarios, con especiales dificultades de integración en el mercado de trabajo, que concluyan con la colocación de aquellos, tales como jóvenes, mujeres, parados de larga duración, mayores de 45 años, discapacitados e inmigrantes.

- Disponer de sistemas electrónicos compatibles y complementarios con los servicios públicos de empleo, con lo que se contribuirá a la obtención de un servicio más rápido y eficaz.

- Garantizar el cumplimiento de la normativa laboral y de seguridad social.

- Observar las normas sobre accesibilidad universal de las personas con discapacidad, haciendo especial hincapié en evitar su exclusión en el acceso al empleo.

- Con el establecimiento de este conjunto de obligaciones se busca obtener cierta coordinación y colaboración con los servicios públicos de empleo, pero, sobre todo, se persigue que a raíz de

51 En este sentido, ver VALdÉs DAL-RÉ, Fernando. Ob. cit., p. 241 y Fernández Collados, María Belén. "Servicio público de empleo y agencia de colocación", p. 234

52 Ver Morón Prieto, Ricardo. Ob. cit., p. 58; FeRnández Collados, María Belén. «Servicio público de empleo y agencia de colocación», pp. 230-231 o VALDÉs DAL-RÉ, Fernando. Ob. cit., p. 233. 
la legalización de las agencias de colocación con ánimo de lucro, los servicios públicos de empleo no se conviertan en oficinas de asistencia social de intermediación, mientras que las agencias privadas colocan a los desempleados más cualificados. Es por ello, que la ley, tal y como hemos expuesto, obliga a las agencias de colocación a hacer especial hincapié en evitar la exclusión en el acceso al empleo de los discapacitados y a elaborar y ejecutar planes específicos para la colocación de los colectivos prioritarios que concluya con la colocación de aquellos. Si bien, se viene echando en falta que el desarrollo reglamentario no haya especificado los términos en los que se concretan aquellas obligaciones, pues no se ha fijado una cifra máxima de colocación para estos colectivos, considerados prioritarios, que podía haber sido un tanto por ciento basado en el resultado final de colocaciones de la agencia, ni tampoco se condiciona específicamente la renovación o el mantenimiento de la autorización por parte de los servicios públicos de empleo a su cumplimiento, ya que el artículo 14.1.a del real decreto 1796/2010 alude únicamente a la extinción de la autorización por incumplimiento por parte de la agencia de colocación de cualquiera de los requisitos u obligaciones legal o reglamentariamente establecidos ${ }^{53}$.

Como ya advertíamos al comienzo de este apartado, una de las grandes aportaciones al concepto de intermediación laboral es la inclusión en el mismo de las actividades destinadas a la recolocación, lo que supone cumplir legalmente con uno de los objetivos fundamentales de la intermediación laboral: la recolocación de los trabajadores ${ }^{54}$. Así, la ley 35/2010 en su artículo 14, en la nueva redacción dada al artículo 20.2 de la Ley de Empleo, establece que se entiende igualmente como intermediación laboral la actividad destinada a la recolocación de los trabajadores que resultaran excedentes en proceso de reestructuración empresarial cuando aquella hubiese sido establecida o acordada con los trabajadores o sus representantes en los correspondientes planes sociales o programas de recolocación. Por decirlo en otros términos, también tienen la consideración de agentes mediadores en el mercado de trabajo las empresas de outplacement.

En este sentido, la actividad de recolocación o de outplacement proporciona servicios de apoyo, información y asesoramiento al trabajador para la búsqueda de un nuevo empleo lo más adecuado posible a su perfil y preferencia en el menor tiempo posible, reduciendo

53 FERnÁNDEZ ColLAdOS, María Belén. «La intermediación laboral en la reforma de 2010: servicio público de empleo, políticas de empleo y agencias de colocación», pp. 385-386. Asimismo, ver García Ninet, José Ignacio \& SAlido Banús, José Luis. Ob. cit., p. 14.

54 FERNÁNDEZ ColLAdOS, María Belén. «La intermediación laboral en la reforma de 2010: servicio público de empleo, políticas de empleo y agencias de colocación», p. 374. 
así los perjuicios económicos y psicológicos que genera toda situación de despido 55 .

El outplacement es conocido desde los años sesenta en el mercado de trabajo norteamericano y exportado más tarde a Europa, donde desde las instituciones comunitarias se considera como una buena práctica el recurso, en situaciones de reestructuración empresarial, a fórmulas y técnicas destinadas a asegurar una eficiente transición entre empleo y desempleo o a garantizar una adecuada gestión de la trayectoria profesional. Es más, entre las medidas de seguridad en la vida profesional del trabajador en las propuestas de flexiseguridad para el mercado de trabajo en la Unión Europea, se encuadran las medidas que facilitan el proceso de búsqueda de empleo y permiten al trabajador evaluar su situación y competencias y perfeccionar el proceso de búsqueda, a través de un plan personalizado. Las ayudas a la recolocación han venido así a ser consideradas como garantías para el trabajador en el momento de la extinción del contrato, siendo estas medidas más efectivas que las tradicionales indemnizatorias ${ }^{56}$. En tal sentido, las medidas de recolocación se han venido desarrollando desde hace tiempo en Europa, tal cual es el caso, del modelo austriaco e, igualmente, se han venido desarrollando en nuestro país desde hace más de dos décadas, a través de empresas de recursos humanos o consultoras, convirtiéndose sus servicios en un elemento habitual en los planes sociales de los expedientes de regulación de empleo ${ }^{57}$. Si bien, la actividad de recolocación no ha venido gozando de un reconocimiento legal expreso, como sabemos, hasta la normativa de 2010.

A este respecto, como ya hemos advertido, la ley 35/2010 delimita el concepto de intermediación laboral a la actividad destinada a la recolocación de los trabajadores que resulten excedentes en procesos de reestructuración empresarial, cuando aquella hubiera sido establecida o acordada con los trabajadores o sus representantes en los correspondientes planes sociales o programas de recolocación. Por tanto, del precepto legal se desprenden varias conclusiones: primero, que la fuente de intervención de las empresas de recolocación u outplacement puede ser bien la decisión unilateral del empresario (establecida), bien el acuerdo, individual (acordada con los trabajadores) o colectivo (acordada con sus representantes $)^{58}$. Segundo, los medios en los que ha de quedar plasmada la fuente son los planes sociales o los programas de recolocación.

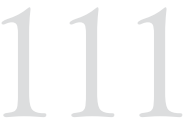

LA REFORMA

DEL MERCADO

DETRABAJO EN

ESPAÑA DURANTE

LA CRISIS

FINANCIERA

INTERNACIONAL

THE LABOR

MARKET REFORM

IN SPAIN

DURING THE

INTERNATIONAL

FINANCIAL CRISIS

55 Sobre el mismo, ver SASTRE CASTILLO, Miguel Ángel. «Outplacement: una aproximación a su realidad teórica». Cuadernos de Relaciones Laborales, 6 (1995), pp. 185-199, p. 187.

56 SÁEZ LARA, Carmen. «Espacio y funciones de las empresas de recolocación». Temas Laborales, 107 (2010), pp. 337-373, p. 339.

57 FERNÁNDEZ ColLADOS, María Belén. «La intermediación laboral en la reforma de 2010: servicio público de empleo, políticas de empleo y agencias de colocación» p. 375 y SÁEZ LARA, Carmen. Ob. cit., p. 341.

58 No obstante, se entiende que no parece que pueda utilizarse la recolocación en supuestos de expedientes de regulación de empleo con plan social, que deben ser resueltos por la autoridad 
Y tercero, que las fuentes y los medios han de insertarse en procesos de restructuración empresarial, no pudiendo recurrirse a empresas de recolocación cuando la pérdida del empleo de los trabajadores se deba a situaciones ajenas a la restructuración empresarial ${ }^{59}$.

Asimismo, se hace necesario aclarar el sentido o el significado que debe atribuirse a las expresiones restructuración empresarial y programas de recolocación. Así, en el primer caso, por reestructuración empresarial, al amparo del artículo 64.5 a) del ET, ha de entenderse las decisiones adoptadas por las empresas de reordenar su plantilla, con cese de la misma, sea total o parcial, siempre que resulte definitivo, incluyéndose en este concepto tanto los despidos colectivos como los despidos objetivos plurales. Siendo irrelevante el número de trabajadores afectados a estos efectos. En segundo término, por programas de recolocación puede entenderse cualquier proyecto unilateralmente adoptado por el empresario o convenido con los trabajadores o sus representantes, que prevea un conjunto ordenado de acciones destinadas a asesorar, formar u orientar profesionalmente a trabajadores excedentes de procesos de reestructuración con vistas a asegurar su reinserción en el mercado laboral. Por tanto, se puede entender que los programas de recolocación pueden formar parte de los planes sociales o también pueden haberse acordado o establecido al margen de aquellos, lo que sucederá en los supuestos en los que la empresa que se reestructura no esté obligada a presentar un plan social en el marco de un Expediente de Regulación de Empleo (ERE) ${ }^{60}$ o cuando la reestructuración se lleve a cabo a través del despido objetivo ${ }^{61}$.

Por otro lado, el real decreto 1796/2010, que desarrolla, como sabemos, las agencias de colocación, con respecto a las empresas de recolocación puntualiza en su artículo 2 que estas son agencias de colocación especializadas y estarán sometidas al régimen legal y reglamentario establecido con carácter general para las agencias de colocación. Por lo que cabe entender que las empresas de recolocación que actúen en los supuestos concretos de recolocación de trabajadores excedentes en procesos de reestructuración empresarial únicamente pueden actuar como agencias de colocación acogiéndose al régimen legal y reglamentario establecido. Por lo que a sensu contrario, cabe afirmar que las empresas y consultorías que hasta la fecha habían venido desarrollando actividades de recolocación pueden continuar haciéndolo siempre que no se trate de la recolocación de trabajadores excedentes

laboral al no haberse concluido con acuerdo el correspondiente período de consultas (GARCÍA NINET, José Ignacio \& SALIDO BANúS, José Luis. Ob. cit., p. 14).

59 VALDÉS DAL-RÉ, Fernando. Ob. cit., p. 236.

60 Así, el artículo 51.4. párrafo segundo del ET establece que, en todo caso, en las empresas de 50 o más trabajadores se deberá acompañar a la documentación iniciadora del expediente de regulación de empleo un plan de acompañamiento social.

61 L. cit. 
en procesos de reestructuración empresarial, para lo que la empresa tendría que convertirse en una agencia de colocación, siendo necesaria la correspondiente autorización por parte de los servicios públicos de empleo ${ }^{62}$.

Por último queremos poner de manifiesto que entre las ventajas del outplacementse suele afirmar que contribuye a disminuir el tiempo de paro del desempleado, si bien no hay una garantía absoluta de éxito, pues la situación de crisis actual reduce este nivel de éxito. Así, se puede apreciar cómo los datos que se refieren a España cifran en un 57\% los candidatos que encontraron nuevo puesto de trabajo en 2009, frente al 65\% alcanzado en 2008. Si bien, se afirma, que lo relevante es que el $76 \%$ consigue colocación antes de un año. Incluso se han descrito efectos positivos sobre las perspectivas salariales de los trabajadores que se benefician de estos programas o servicios ${ }^{63}$. De ahí que, el buen funcionamiento de los servicios de outplacement parece haber despertado al legislador a regular expresamente estos servicios, tal y como hemos analizado. Si bien aun queda un largo camino por recorrer, de modo que debiera llevarse a cabo una regulación más exhaustiva de las actividades de recolocación ${ }^{64}$.

\section{IV.MEDIDAS DE FOMENTO DEL EMPLEO JUVENIL: EL CONTRATO EN PRÁCTICAS Y EL CONTRATO PARA LA FORMACIÓN}

Tal y como ya hemos expuesto, uno de los principales colectivos afectados por la desmesurada tasa de desempleo que viene experimentando nuestro país hace más de dos años, fruto de la crisis económica y financiera por la que estamos atravesando, es el colectivo de los jóvenes, que sufre una tasa de desempleo que se sitúa por encima del $40 \%$, lo que ha colocado a nuestro país a la cabeza de Europa en lo que a este extremo se refiere. De ahí que no hayan faltado en el diseño de la reforma laboral que se ha llevado a cabo en nuestro país medidas específicamente dirigidas a paliar la gravísima situación de desempleo que padece este sector de la población activa. En este sentido, el legislador ha venido a incidir sobremanera en los contratos formativos en sus dos modalidades clásicas, esto es, el contrato en prácticas y el contrato para la formación, con el claro objetivo de potenciar su uso como herramienta capital de incentivación de la inserción laboral de los trabajadores jóvenes. Por

62 FERNÁNDEZ Collados, María Belén. «La intermediación laboral en la reforma de 2010: servicio público de empleo, políticas de empleo y agencias de colocación», p. 381.

63 SÁEZ LARA, Carmen. Ob. cit., p. 347.

64 En esta línea, ver DE VICENTE PACHÉS, Fernando. «Intermediación laboral y agencias de colocación». Comunicación presentada a la II Ponencia «Reformas en materia de políticas activas de ocupación». Sesión 1, «La intermediación laboral». XXII Jornadas catalanas de Derecho Social: «Las reformas laborales de 2010", Lleida: marzo de 2011, p. 10.

LA REFORMA

DEL MERCADO

DETRABAJO EN

ESPAÑA DURANTE

LA CRISIS

FINANCIERA

INTERNACIONAL

THE LABOR

MARKET REFORM

IN SPAIN

DURING THE

INTERNATIONAL

FINANCIAL CRISIS 
tanto, procederemos a continuación al análisis por separado de cada uno de estos contratos, con el fin de examinar las modificaciones más significativas introducidas a este respecto en cada uno de ellos.

Así, por lo que se refiere al contrato en prácticas, que tiene como finalidad la aportación de conocimientos prácticos al bagaje teórico que ya se acredita a través de la oportuna titulación $\mathrm{n}^{65}$, sin que se precise, pues, una formación teórica adicional, la ley 35/2010 viene a modificar su regulación, contenida en el artículo 11.1 del ET, en diferentes aspectos, de los cuales consideramos fundamentales: la ampliación de los títulos habilitantes para concretar un contrato en prácticas y del período en el que se puede celebrar el mismo y el establecimiento de diferentes limitaciones a dicho contrato.

Por tanto, en primer término, por lo que se refiere a la titulación habilitante para poder concertar este tipo de contratos, siendo esta la esencia de este contrato cuyo bagaje de conocimientos debe ponerse en práctica en una empresa, la ley amplía el círculo de sujetos que pueden celebrar un contrato en prácticas, al aumentar el elenco de títulos que permiten concretar este tipo de contratos.

Así, con anterioridad a la reforma de 2010 solo resultaban admisibles para poder celebrar este contrato los títulos universitarios y los de formación profesional de grado medio o superior, así como los títulos oficialmente reconocidos como equivalentes «que habiliten para el ejercicio profesional ${ }^{66}$. Mientras que a raíz de la reforma operada en 2010 se añade al elenco de títulos que posibilitan celebrar un contrato en prácticas los certificados de profesionalidad que capaciten para el ejercicio profesional de acuerdo con lo establecido en la ley orgánica 5/2002, de 19 de junio, Ley de las Cualificaciones y de la Formación Profesional. Los mismos, a tenor de dicha normativa, vendrán a acreditar la correspondiente cualificación profesional a quienes los hayan obtenido y surgen los correspondientes efectos académicos, entendiéndose por cualificación profesional el conjunto de competencias profesionales con significación para el empleo que pueden ser adquiridas mediante formación modular u otros tipos de formación y a través de la experiencia laboral ${ }^{67}$. Añadiéndose además que el puesto de trabajo a desempeñar deberá permitir la obtención de una práctica profesional adecuada al nivel de estudios o de formación cursados.

En segundo término, otro de los aspectos modificados con relación a este contrato ha sido el período en el que se puede celebrar el mismo.

65 Cabeza Pereiro, Jaime. «Sobre los contratos formativos a la vista de la reforma de 2010». Revista General de Derecho del Trabajo y de la Seguridad Social. Publicación en línea, 24 (2011), p. 1.

66 Ibídem, p. 2 y CAVAS MARTínEZ, Faustino. "La reforma de los contratos formativos y el fomento del empleo juvenil». En Montoya Melgar, Alfedo \& CAVAS Martínez, Faustino (dirs.). Ob. cit., p. 166.

67 Sobre esta ampliación, Morón PRIETO, Ricardo. Ob. cit., p. 54; CABEZA PEREIRO, Jaime. Ob. cit., p. 3 o CAVAS MARTínez, Faustino. Ob. cit., pp. 166-167. 
Sin querer detenernos en exceso en esta cuestión, queremos apuntar que el establecimiento de un arco temporal para la celebración de este contrato se justifica por la necesidad de garantizar la proximidad entre los estudios realizados y las prácticas a desarrollar. Si bien, con la clara intención de incrementar las oportunidades de empleo e inserción laboral de los desempleados jóvenes se ha ampliado de cuatro a cinco años, contados desde la terminación de los correspondientes estudios, el plazo en el que se puede concretar este contrato. Asimismo, en orden a favorecer la inserción laboral de las personas discapacitadas, se amplía el plazo de seis a siete años cuando el contrato se concierte con trabajadores discapacitados ${ }^{68}$. En este sentido, un aspecto a tener en cuenta es que el contrato en prácticas no establece límite de edad, sino únicamente que el trabajador haya finalizado sus estudios en el arco temporal que hemos visto ${ }^{69}$.

Por último, otro de los aspectos que consideramos de importancia, en cuanto a las modificaciones introducidas por la Ley con relación a este contrato, es el establecimiento de determinadas restricciones o limitaciones al mismo, con el fin de evitar posibles abusos por parte de los empresarios a la hora de recurrir a dicho contrato. Dichas limitaciones son, básicamente, las siguientes ${ }^{70}$ :

- Ningún trabajador podrá estar contratado en prácticas en la misma o distinta empresa por tiempo superior a dos años ${ }^{71}$ en virtud de la misma titulación o certificado de profesionalidad.

- Igualmente, no se podrá estar contratado en prácticas en la misma empresa para el mismo puesto de trabajo por tiempo superior a dos años, aunque se trate de distinta titulación o distinto certificado de profesionalidad.

- Asimismo, no se podrá concertar un contrato en prácticas sobre la base de un certificado de profesionalidad obtenido como consecuencia de un contrato para la formación celebrado anteriormente con la misma empresa.

Por tanto, al margen de estas reformas introducidas en el contrato en prácticas, que han tratado de ampliar su ámbito de aplicación subjetivo y temporal, favoreciendo así el empleo de esta figura, y que han tratado de

68 Ver CABeza PeReiRo, Jaime. Ob. cit., pp. 4 y ss. y MoReno MÁRQUeZ, Ana María. «Los contratos formativos». Temas Laborales, 107 (2010), pp. 123-161, pp. 129-130.

69 CABEZA PereIRo, Jaime. Ob. cit., p. 170.

70 Para ahondar más en estas restricciones o limitaciones, ver MORENO MÁRQUEZ, Ana María. Ob. cit., pp. 130 y ss. o CAVAS MARTínEZ, Faustino. Ob. cit., pp. 172-173.

71 Que es el plazo máximo que se fija en cuanto a la duración del contrato, que oscila entre seis meses y dos años, el cual no se ha visto alterado por la reforma. Contemplándose, únicamente, a este respecto diferentes supuestos que interrumpen la duración del contrato, tales como: la situación de incapacidad temporal, riesgo durante el embarazo, maternidad, adopción o acogimiento, riesgo durante la lactancia y paternidad.

LA REFORMA

DEL MERCADO

DETRABAJO EN

ESPAÑA DURANTE

LA CRISIS

FINANCIERA

INTERNACIONAL

THE LABOR

MARKET REFORM

IN SPAIN

DURING THE

INTERNATIONAL

FINANCIAL CRISIS 
evitar, en la medida de lo posible, los abusos empresariales en el empleo de la misma; las reformas de mayor calado y enjundia se han producido en el contrato para la formación, convirtiéndose este en el instrumento estandarte de lucha contra el desempleo juvenil. Prueba de ello es que la reforma, tal y como veremos, se ha centrado, básicamente, en incorporar elementos que hagan atractivo su uso tanto para el empresario (a través de una bonificación de las cotizaciones sociales, según veremos) como para los trabajadores (a través de una mejora retributiva y una mejora de la protección social).

Así, el contrato, que para la formación tendrá por objeto la adquisición de la formación teórica y práctica necesaria para el desempeño adecuado de un oficio o de un puesto de trabajo que requiera un determinado nivel de cualificación, solo podrá celebrarse con quienes carezcan de la titulación o certificado de profesionalidad necesarios para realizar un contrato en prácticas, pudiendo celebrarse el mismo con trabajadores mayores de 16 años y menores de 21, con lo que dicho contrato tiene como destinatarios exclusivos a la población juvenil. Lo que lo dota de una notable diferencia con relación al contrato en prácticas, puesto que aquel contrato no establece límite de edad, sino únicamente que el trabajador haya finalizado sus estudios en el arco temporal que expusimos, lo que no convierte a los jóvenes en destinatarios exclusivos, aun cuando sí principales. No obstante, una de las novedades introducidas con relación al contrato para la formación, en lo que a la edad de los sujetos destinatarios se refiere, es que como medida transitoria, con el fin de favorecer la inserción laboral de los jóvenes, se establece que hasta 31 de diciembre de 2011 podrán celebrarse contratos para la formación con trabajadores menores de 25 años. Asimismo, se prevé que cuando el contrato se concierte con desempleados que se incorporen como alumnos-trabajadores a los programas públicos de empleo-formación, tales como los de escuelas taller, casas de oficios, talleres de empleo u otros que se puedan aprobar, el límite máximo de edad será el establecido en las disposiciones que regulen el contenido de los citados programas. En el supuesto de desempleados que cursen un ciclo formativo de formación profesional de grado medio, el límite máximo de edad será de veinticuatro años. Además, en orden a favorecer la inserción de las personas discapacitadas, se mantiene que el límite de edad no será de aplicación cuando el contrato se concierte con personas con discapacidad $^{72}$.

Al margen de la ampliación del ámbito subjetivo de este contrato, lo que más nos interesa conocer en estos momentos son las instrumentos que se han introducido para hacerlo más atractivo tanto para empresarios

72 En este sentido, ver Morón Prieto, Ricardo. Ob. cit., p. 59; MoReno MÁRQUeZ, Ana María. Ob. cit., p. 141; Cabeza Pereiro, Jaime. Ob. cit., pp. 7-8 y Cavas Martínez, Faustino. Ob. cit., p. 176. 
como para trabajadores, tratando, así, de potenciar su uso, al objeto de lograr una mayor inserción en el mercado de trabajo de los jóvenes desempleados.

Así, en primer término, por lo que se refiere a las medidas establecidas por la reforma de 2010 para hacer este tipo de contrato más atractivo para los empresarios, la ley contempla los siguientes incentivos:las empresas que a partir del 19 de septiembre de 2010 y hasta el 31 de diciembre de $2011^{73}$ celebren contratos para la formación con trabajadores desempleados e inscritos en las oficinas de empleo tendrán derecho durante la vigencia del contrato, incluidas las prórrogas, a una bonificación del 100\% de las cuotas empresariales a la Seguridad Social por contingencias comunes, así como las correspondientes a accidentes de trabajo y enfermedades profesionales, desempleo, Fondo de Garantía Salarial (FOGASA) y formación profesional, referidas a dichos contratos. La misma bonificación se aplica a la cuota de los trabajadores. Ahora bien, la ley exige, para tener derecho a tales incentivos, que el contrato para la formación suponga un incremento de la plantilla de la empresa. Por tanto, dicha bonificación no será aplicable si la empresa procede a contratar a un trabajador con un contrato para la formación para sustituir a otro trabajador fijo que haya causado baja en la misma ${ }^{74}$.

Asimismo, debe tenerse en cuenta, con relación a estas bonificaciones, que las mismas no serán de aplicación a los contratos para la formación suscritos con los alumnos trabajadores participantes en los programas de escuelas taller, casas de oficio y talleres de empleo.

Por último, con relación a la mismas, debe tenerse en cuenta que la ley prevé que el Gobierno evalúe con anterioridad al 31 de diciembre de 2011 el funcionamiento de esta medida. A la vista de dicha evaluación, y en función de la evolución del empleo durante 2010 y 2011, el Gobierno, previa consulta con las organizaciones sindicales y empresariales más representativas, adoptará las medidas que correspondan sobre su prórroga o modificación ${ }^{75}$.

Ahora bien, a pesar del establecimiento de estas bonificaciones, no basta con establecer determinadas mejoras en la regulación del contrato para la formación desde el punto de vista del empresario, con el objeto de incentivarle para que recurra a la utilización de este tipo de contrato, sino que es preciso adoptar medidas dirigidas a los trabajadores, con el objeto de que estos encuentren atractivo someterse a este tipo de

73 Igualmente, se aplica esta bonificación a los contratos para la formación celebrados con anterioridad a la entrada en vigor de la ley $35 / 2010$ que sean prorrogados entre dicha fecha y el 31 de diciembre de 2011, durante la vigencia de dichas prórrogas.

74 Para el cómputo del incremento de la plantilla la ley se remite a lo dispuesto en el párrafo segundo de su artículo 10.5. Para mayor detalle sobre este requisito, ver MORENO MÁRQUEZ, Ana María. Ob. cit., pp. 152-153 y CAVAS MARTínEZ, Faustino. Ob. cit., pp. 184-185.

75 Así lo establece la disposición adicional duodécima de la ley 35/2010.

LA REFORMA

DEL MERCADO

DETRABAJO EN

ESPAÑA DURANTE

LA CRISIS

FINANCIERA

INTERNACIONAL

THE LABOR

MARKET REFORM

IN SPAIN

DURING THE

INTERNATIONAL

FINANCIAL CRISIS 
contrato. Dichas medidas, tal y como hemos adelantado, vienen dirigidas a proporcionar a aquellos una mejora de las condiciones retributivas y una mejora de la acción protectora de la seguridad social.

En este sentido, por lo que se refiere a la mejora de las condiciones retributivas de los trabajadores sometidos a este tipo de contrato, hay que resaltar que con anterioridad a la reforma el artículo $11.2 \mathrm{~h}$ ) del ET establecía que la retribución del trabajador sería la establecida en el convenio colectivo, sin que, en su defecto, pueda ser inferior al salario mínimo interprofesional en proporción al tiempo de trabajo efectivamente realizado. Con lo que dicha regulación al contener la expresión en su defecto, parecía contener una remisión plena al convenio colectivo en cuanto a la fijación de la retribución de los trabajadores en formación, por lo que la garantía constituida por el salario mínimo interprofesional solo era aplicable en ausencia de convenio colectivo. Pues bien, a partir de la reforma introducida por la ley 35/2010 se lleva a cabo una modificación del régimen retributivo con la supresión de la expresión «en su defecto» y con la diferenciación entre el primer y el segundo año de contrato. Lo que viene a significar, en primer término, que a raíz de la supresión de aquella expresión, el convenio colectivo, al establecer la retribución de estos trabajadores, actuará condicionado por el importe del salario mínimo interprofesional fijado, como sabemos, por el Gobierno. Esto es, la ley establece un mínimo que el trabajador tendrá garantizado, ya que el convenio colectivo no podrá establecer una cuantía inferior, aun cuando, como es lógico, si podrá mejorarla. Y, en segundo término, la ley distingue entre el primer y segundo año de retribución del contrato. Así, durante el primer año de vigencia del contrato se prevé que la retribución será la fijada en el convenio colectivo, sin que pueda ser inferior al salario mínimo interprofesional en proporción al tiempo de trabajo efectuado, esto es, excluyendo el tiempo dedicado a la formación teórica. Mientras que a partir del segundo año de vigencia del contrato, la retribución será la fijada en convenio colectivo, sin que en ningún caso pueda ser inferior al salario mínimo interprofesional, con independencia del tiempo dedicado a la formación teórica. Con lo que el legislador lleva a cabo una mejora retributiva a partir del segundo año de vigencia del contrato ${ }^{76}$.

Por otro lado, por lo que se refiere a la mejora de la acción protectora de la seguridad social, esta es una de las innovaciones más importantes que ha venido a establecer la ley 35/2010 con relación a este tipo de contratos. De este modo, la ley establece que la acción protectora comprenderá todas las contingencias, las situaciones protegibles y las prestaciones, incluido el desempleo, añadiendo que, asimismo, se tendrá derecho a la 
cobertura del FOGASA ${ }^{77}$. En este sentido, la gran novedad, sin duda, es el expreso otorgamiento que efectúa la norma de la protección por desempleo, con el claro fin de hacer más atractivo para los jóvenes el contrato para la formación, tal y como se señala en el preámbulo de la ley $35 / 2010^{78}$. No obstante, con relación a la prestación por desempleo hay que tener en cuenta que dicha prestación viene a ser excluida por la ley en los contratos para la formación suscritos con alumnos trabajadores en los programas de escuelas taller, casas de oficios y talleres de empleo ${ }^{79}$.

Hasta aquí, el análisis de algunos de los principales instrumentos o medidas que se han puesto en marcha en nuestro país con el firme propósito de procurar el acceso al mercado de trabajo de la población más joven. Si bien, como ahora veremos, no son estos los únicos instrumentos que se han puesto en marcha, a raíz de la reforma de 2010, con aquel fin. Sino que habrá de tenerse, igualmente, en cuenta el régimen de incentivos a la contratación establecido en la ley 35/2010, dirigido, del mismo modo, a los jóvenes y a otros colectivos considerados prioritarios, los cuales presentan especiales dificultades de inserción en el mercado de trabajo, y para los cuales se trata de facilitar el acceso al mercado laboral, estableciendo mecanismos que estimulen su contratación, tal cual ocurre con el mencionado régimen de incentivos a la contratación. Pasaremos, pues, a analizar los aspectos más destacados o relevantes que presenta el mismo, aun cuando sin intención de efectuar un examen exhaustivo de los mismos.

\section{EL RÉGIMEN DE INCENTIVOS A LA CONTRATACIÓN COMO MEDIDA DE FOMENTO DE EMPLEO}

La expresión incentivos estatales al empleo ha quedado reducida a las bonificaciones a la contratación, las cuales suponen una rebaja, y en algunos casos incluso una exención, para el empresario del pago de las cuotas a la seguridad social por la contratación de colectivos que presentan unas mayores dificultades para insertarse en el mercado de $\operatorname{trabajo}^{80}$. Dichas bonificaciones, en cuanto medida de fomento de empleo, constituyen, desde el punto de vista económico, la principal política activa del mercado de trabajo de nuestro país en

77 Esta ampliación de la acción protectora de la Seguridad Social solo se aplica a los contratos para la formación que se hayan concertado a partir del 18 de junio de 2010, fecha de entrada en vigor del Real Decreto Ley 18/2010, y a los contratos con anterioridad a esa fecha, una vez que sean prorrogados (párrafo segundo de la disposición transitoria octava de la ley 35/2010, en los mismos términos que se establecía en la disposición transitoria octava del Real Decreto Ley 18/2010).

78 Debe tenerse en cuenta a este respecto, el establecimiento del régimen de cotización por desempleo en este contrato, así como la cuantía de la prestación (ver CAVAS MARTínEZ, Faustino. Ob. cit., pp. 180-181; Moreno MÁRQUeZ, Ana María. Ob. cit., pp. 150-151; CABEZA PEREIRO, Jaime. Ob. cit., pp. 18 y ss. y GONZÁLEZ ORTEGA, Santiago. Ob. cit., pp. 429-430).

79 Así se establece en la disposición adicional tercera de la ley 35/2010.

80 Morales Ortega, José Manuel. Ob. cit., p. 380.

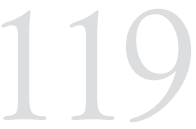

LA REFORMA

DEL MERCADO

DE TRABAJO EN

ESPAÑA DURANTE

LA CRISIS

FINANCIERA

INTERNACIONAL

THE LABOR

MARKET REFORM

IN SPAIN

DURING THE

INTERNATIONAL

FINANCIAL CRISIS 
términos de gasto ${ }^{81}$ y jurídicamente una pieza ya tradicional de nuestras políticas públicas de empleo ${ }^{82}$. De hecho, la Unión Europea ${ }^{83}$ ha venido afirmando desde hace años que las mismas se han convertido en la piedra angular de nuestra política de empleo. No obstante, debe advertirse que desde la Unión Europea no se contempla ninguna propuesta con relación con esta medida de bonificaciones a la contratación. Esto es, ni siquiera en la Estrategia Europea 2020 se menciona este abaratamiento de la mano de obra como una medida eficaz de lucha contra el desempleo. Desde las instituciones comunitarias se prefieren enfatizar todas aquellas medidas que redunden en la empleabilidad del trabajador, esto es, en su formación ${ }^{84}$.

Pese a todo, habida cuenta de que este instrumento, tal y como se ha apuntado, es una pieza tradicional en nuestra política de empleo, a pesar de que el mismo ha venido arrojando dudas y críticas acerca de su verdadera eficacia ${ }^{85}$, es por ello que el mismo merece toda nuestra atención en estos momentos. Por lo que trataremos de analizar en las próximas páginas el marco que presenta esta medida de bonificaciones a la contratación a raíz de la reforma operada en 2010, a fin de explorar cuáles son los instrumentos que se han establecido con relación a la misma para lograr a través de ella una fomento del empleo y una consiguiente reducción de la altísima tasa de desempleo que, como es consabido, presenta nuestro país.

Debe partirse de la base de que la política de empleo actual tiene como finalidad la calidad en el empleo, loque se viene traduciendoen estabilidad en el empleo. Y este parece ser el espíritu de estas bonificaciones a la contratación en nuestro país, donde, como sabemos, la temporalidad es demasiado elevada. Así, las mismas desde sus comienzos hasta la propia ley 35/2010 son concedidas para la contratación indefinida y la transformación en indefinidos de los contratos formativos, de relevo y de sustitución por anticipación de la edad de jubilación, con lo que se persigue conseguir el doble objetivo de inserción en el mercado laboral

81 CUETO IGLESIAS, Begoña. «Las ayudas a la contratación indefinida en España». Revista de Economía Laboral, 3 (2006), pp. 87-199, p. 88.

82 Montoya Melgar, Alfredo (ed.). Comentario a la reforma laboral de 2006: ley 43/2006, de 9 de diciembre. Navarra: Thomson Civitas, 2007, p. 53.

83 Así, en el Informe Conjunto sobre el empleo de 1999, ya se afirmaba que «la reducción de los costes laborales a través de las subvenciones a la seguridad social sigue siendo la piedra angular de la promoción del empleo en España».

84 Morales OrTega, José Manuel. Ob. cit., p. 381.

85 Así, se ha venido a afirmar que una política de bonificaciones generosas, puede conducir a un comportamiento por parte del empresario que aumenta la rotación laboral, ya que el empresario contrata y despide una vez que el trabajador ya no le da derecho a reducciones en la cuota empresarial a la Seguridad Social y cuando el coste del despido es todavía bajo (ver CUETO IGLESIAS, Begoña. Ob. cit., p. 104). Asimismo, se viene dudando de que estas subvenciones sean beneficiosas para las carreras posteriores de los beneficiarios y se viene advirtiendo de los modestos efectos sobre el empleo de las mismas (ver MARX, Ive. «Subvenciones al empleo y reducción de las cotizaciones empresariales. Dictamen de los estudios empíricos». Revista Internacional del Trabajo, CXX, 1(2001), pp. 75-148, pp. 75 y ss. 
de los colectivos con mayores dificultades de inserción en el mismo y, lo que es más importante aun, hacerlo de manera indefinida, logrando de este modo alcanzar calidad en el empleo. Esto es, procurando no solo luchar contra el desempleo sino mantener el empleo.

Pasando ya al examen de alguno de los aspectos concretos de esta medida, en primer término, queremos destacar que la ley 35/2010 ha roto con la tendencia de los anteriores programas de empleo que paulatinamente fueron aumentando el número de colectivos beneficiarios de estas bonificaciones. Y es que, tal y como se recoge en el preámbulo de aquella norma, se viene a afirmar que «se mejora la política de bonificaciones a la contratación indefinida, partiendo del consenso general de que su práctica generalizada ha limitado gravemente su eficacia» ${ }^{86}$.

Asimismo, antes de entrar a analizar los colectivos concretos hacia los que ahora se dirige esta medida, queremos llamar la atención sobre dos aspectos concretos, por un lado, dentro de este nuevo marco se ha institucionalizado la evaluación permanente del sistema. Así, la disposición adicional novena de la ley 35/2010 establece que el Gobierno presentará ante el Congreso de los Diputados un informe anual de evaluación y seguimiento económico de las bonificaciones a la contratación con el fin de conocer la efectividad de la medida a fin de ajustar las políticas activas a la realidad del mercado laboral. Y, por otro lado, la ley 35/2010 no se limita a lo económico, ya que establece que los trabajadores cuya contratación resulta bonificada serán objetivo prioritario en los planes de formación para personas ocupadas dentro de los programas de formación profesional para el empleo, así como de cualquier otra medida de política activa de empleo, con el objeto de incrementar su cualificación profesional. Con ello se busca que la bonificación sea, igualmente, un instrumento que coopere conla empleabilidad del trabajador. Aun cuando parece que esta previsión por ser demasiado inconcreta es más una declaración de buenas intenciones ${ }^{87}$.

Por cuanto hace al colectivo al que va dirigida esta medida, tal y como hemos apuntado, la norma toma conciencia de que la generalización de la misma ha limitado su eficacia, por lo que la ley realiza una regulación más rigurosa y define de manera más selectiva los colectivos de trabajadores para cuya contratación indefinida se establecen bonificaciones. Veamos, pues, los destinatarios de esta medida de fomento del empleo.

86 En este sentido, CÁMARA BOTÍA, Alberto. «La bonificación de cuotas para fomentar la contratación indefinida: el art. 10 de la Ley 35/2010». En Montoya MELGAR, Alfedo \& CAvas MartíneZ, Faustino (dirs.). Ob. cit., pp. 304 y ss. En este sentido, se afirma desde la OIT que la eficacia de medidas de este tipo es mayor cuando se orienta hacia una población con una desventaja determinada, en lugar de orientarla a una población más amplia (ver OIT/IIEL. Ob. cit.,p. 10).

87 Morales ORTEGA, José Manuel. Ob. cit., p. 389.

LA REFORMA

DEL MERCADO

DETRABAJO EN

ESPAÑA DURANTE

LA CRISIS

FINANCIERA

INTERNACIONAL

THE LABOR

MARKET REFORM

IN SPAIN

DURING THE

INTERNATIONAL

FINANCIAL CRISIS 
En primer término debemos hacer referencia a los jóvenes, debido a la especial virulencia con la que viene padeciendo este colectivo la crisis del empleo. En este sentido, debemos partir de la base de que la delimitación del concepto joven abarca a las personas entre 16 y 30 años. La ley 35/2010, en contra de lo que establecía la ley 46/2003, limita notoriamente el ámbito de la bonificación al exigir que estos jóvenes presenten especiales problemas de empleabilidad. Entendiendo por tales que hayan estado inscritos en la Oficina de Empleo, al menos, 12 meses en los 18 meses anteriores a la contratación y que no hayan completado la escolaridad obligatoria o carezcan de titulación profesional. Con relación a la cuantía, la misma consiste en una cantidad a tanto alzado y fija, tal cual se estableció en el Programa de Empleo de 2006, que no tiene en cuenta el salario del trabajador ni su productividad. Así, la ley prevé para el caso de contratación de jóvenes una bonificación a la cuota empresarial de la Seguridad Social de 66,67 euros/mes (800 euros al año), durante tres años o, en su caso, por su equivalente diario. Cuando estos contratos se realicen con mujeres las bonificaciones serán de 83,33 euros/mes (1000 euros al año) o su equivalente diario ${ }^{88}$.

En segundo término, debemos hacer referencia a los mayores de 45 años. En este sentido, debe advertirse que la inclusión de este colectivo en los destinatarios de esta medida se debe, por un lado, al envejecimiento de la población, de ahí que se promueva por parte de las instituciones internacionales la prolongación de la vida activa. Y, por otro lado, a las enormes dificultades con las que se encuentra este colectivo a la hora de reincorporarse al mercado laboral, debido a su edad. En relación a este colectivo la ley 35/2010 añade un requisito adicional al de la edad para que se pueda acceder a la bonificación, y es que se haya estado inscrito en la Oficina Pública de Empleo, al menos, doce meses en los dieciocho meses anteriores a la contratación. Con lo que se viene a incorporar aquí el requisito de desempleo de larga duración. Además, se ha llevado a cabo en la ley una destacada reducción de la bonificación, ya que ahora su duración es de solo tres años frente a toda la vida del contrato de la regulación anterior. De este modo, las empresas que contraten, hasta el 31 de diciembre de 2011, de forma indefinida a trabajadores desempleados mayores de 45 años, que hayan estado inscritos en la Oficina de Empleo, al menos, doce meses en los dieciocho meses anteriores a la contratación, tendrán derecho a una bonificación en la cuota empresarial a la Seguridad Social, de 100 euros/mes (1200 euros/ año), durante tres años o, en su caso, por su equivalente diario. Si estos contratos se conciertan con mujeres las bonificaciones serán de 116,67 euros/mes (1400 euros/año) o en su equivalente diario. No obstante, colectivo, el régimen de bonificaciones con relación a los contratos para la formación. 
a este colectivo parece que no le ha beneficiado la reducción de la duración de la bonificación comentada, puesto que la disminución del tiempo de abaratamiento de los costos laborales, provoca, lógicamente, una pérdida del interés empresarial por esta medida. Tal es así, que el número de contratos bonificados celebrados con este colectivo no es relevante ${ }^{89}$.

Se mantienen las bonificaciones para la contratación indefinida de otros colectivos que se consideran prioritarios, debido, igualmente, a sus problemas de inserción en el mercado de trabajo. Así, se mantienen en su regulación actual las bonificaciones dirigidas a las personas discapacitadas $^{90}$, víctimas de violencia de género ${ }^{91}$ y trabajadores en situación de exclusión social ${ }^{92}$.

Además de estos incentivos a los que hemos hecho referencia, deben tenerse en cuenta, en estos momentos, las nuevas bonificaciones por contratos a tiempo parcial que se contemplan en el Real Decreto Ley 1/2011, de 11 de febrero, de Medidas Urgentes para Promover la Transición al Empleo Estable, con el que se persigue aumentar las posibilidades de empleo estable y la colocación del gran número de personas desempleadas, especialmente, jóvenes y parados de larga duración. De este modo, podrán acogerse a las bonificaciones previstas en la norma las empresas que contraten, dentro del período de los doce meses siguientes a la entrada en vigor de esta norma, de forma indefinida o temporal, a personas desempleadas inscritas ininterrumpidamente en la oficina de empleo, al menos, desde el 1 de enero de 2011, mediante un contrato de trabajo a tiempo parcial, y que reúnan alguno de estos requisitos: 1) tener una edad igual o inferior a 30 años, 2) Llevar inscritas en la Oficina de Empleo, al menos, doce meses en los dieciocho meses anteriores a la contratación. Si bien, la jornada de trabajo de estos contratos deberá estar entre el $50 \%$ y el $75 \%$ de la de un trabajador a tiempo completo comparable.

En estos casos, las empresas tendrán derecho, durante los doce meses siguientes a la contratación, a una reducción del 100\% en todas las cuotas empresariales a la Seguridad Social, si el contrato se realiza por empresas cuya plantilla sea inferior a 250 personas, o del $75 \%$, en el supuesto de que la empresa contratante tenga una plantilla igual o superior a esa cifra. No obstante, en los supuestos de contratos

89 Morales Ortega, José Manuel. Ob. cit., p. 393.

90 Artículos 2.2 y 3 de la ley 46/2003, de 16 de diciembre, Ley de Empleo.

91 Artículo 2.4 de la ley 46/2003, de 16 de diciembre, Ley de Empleo. Asimismo, debe tenerse en cuenta el real decreto 1917/2008, donde en el artículo 2.d) se contiene un catálogo de medidas de actuación a favor de la mujer víctima de la violencia de género, donde se incorporan los incentivos para las empresas que las contraten. A partir de este real decreto, la bonificación asciende a 1500 euros durante los primeros cuatro años de la contratación. Cuantía que se reduce en los casos de contratación a tiempo parcial o temporal.

92 Artículo 2.5 de la ley 46/2003, de 16 de diciembre, Ley de Empleo.

\section{LA REFORMA \\ DEL MERCADO}

DE TRABAJO EN

ESPAÑA DURANTE

LA CRISIS

FINANCIERA

INTERNACIONAL

THE LABOR

MARKET REFORM

IN SPAIN

DURING THE

INTERNATIONAL

FINANCIAL CRISIS 
temporales, podrán acceder a las reducciones de cuotas reguladas en este artículo los que se concierten por una duración inicial prevista igual o superior a seis meses, mediante cualquier modalidad de contratación de duración determinada o temporal, incluida la modalidad del contrato en prácticas, que permita su celebración a tiempo parcial conforme a lo establecido legalmente. No pudiendo, en ningún caso, aplicarse esta reducción a los contratos de trabajo celebrados bajo las modalidades de interinidad y de relevo ${ }^{93}$.

Por otro lado, ya decíamos que esta medida respondía a una doble finalidad, ya que la misma viene procurando no solo luchar contra el desempleo sino mantener el mismo. Así, por lo que se refiere al mantenimiento del empleo, se prevé en la ley la conversión en indefinidos de los contratos formativos, de relevo y de sustitución por anticipación de la edad de jubilación. En este sentido, la principal novedad que introduce la reforma de 2010 es el señalamiento de un término final para realizar la conversión bonificable y la modificación en la duración de la bonificación. De este modo las empresas que, hasta el 31 de diciembre de 2011, transformen en indefinido contratos formativos, de relevo y de sustitución por anticipación de la edad de jubilación, cualquiera que sea la fecha de su celebración, tendrán derecho a una bonificación en la cuota empresarial a la Seguridad Social de 41,67 euros/mes (500 euros/ año), durante tres años o, en su caso, por su equivalente diario. En el caso de mujeres dichas bonificaciones serán de 58,33 euros/mes (700 euros/año) o, en su caso, por su equivalente diario ${ }^{94}$. No obstante, esta medida no parece arrojar resultados positivos en cuanto instrumento de mantenimiento del empleo, puesto que si nos atenemos a los datos estadísticos, las conversiones de contratos temporales en indefinidos ascendieron en 2010 a 29 937, de las cuales solo 1603 pudieron dar lugar a la bonificación por provenir de cualquiera de los contratos temporales con derecho a ella. Así, solo el 5,35\% de las conversiones pueden ser resultado de la correspondiente bonificación frente al $69,11 \%$ que suponen las conversiones del contrato eventual por circunstancias de la producción ${ }^{95}$. Posiblemente, el problema con el que se encuentran estos incentivos es que estos resultan poco atractivos para los empresarios al limitar los contratos temporales al listado mencionado anteriormente. Por lo que se haría aconsejable la extensión de este tipo de bonificaciones a las conversiones de cualquier contrato temporal, careciendo de sentido alguno aquella limitación de los contratos temporales.

93 No obstante, este régimen de bonificaciones no parece que guarde mucho la línea con las directrices que se vienen marcando desde la OIT. Así, a este respecto, dicha Organización viene afirmando que «todo intento de promover el empleo a tiempo parcial debería centrarse en disminuir las diferencias en términos de prestaciones entre los trabajadores a tiempo completo y a tiempo parcial, como han logrado otros países de la UE, por ejemplo, Países Bajos, en lugar de proporcionar incentivos financieros indiscriminados por la contratación a tiempo parcial» (OIT/IIEL. Ob. cit., p. 14).

94 CÁmARA BOtíA, Alberto. Ob. cit., pp. 318-319.

95 Morales OrTEGA, José Manuel. Ob. cit., p. 399. 
Por último, queremos poner de manifiesto, por lo que se refiere a este régimen de bonificaciones, que la ley 35/2010 establece estrictos requisitos a la empresa que contrata y se beneficia de la bonificación en términos de creación de empleo indefinido. Así, dicha ley dispone que será requisito imprescindible para que puedan aplicarse las bonificaciones, que las nuevas contrataciones o transformaciones, salvo las referidas a contratos de relevo, supongan un incremento del nivel de empleo fijo de la empresa ${ }^{96}$. Asimismo, la empresa tendrá que mantener, durante el período de duración de la bonificación, el nivel de empleo fijo alcanzado con la contratación indefinida o transformación bonificada. Además, como el objetivo es el aumento del empleo, su incumplimiento obligará a la empresa a contratar o convertir en indefinido en el plazo de dos meses a otro trabajador. De lo contrario, tendrá que reintegrar las cantidades obtenidas con la bonificación ${ }^{97}$. Sin duda, el objetivo de esta medida es evitar el efecto sustitución que hace que, para beneficiarse de los incentivos a la contratación, las empresas procedan a sustituir empleo fijo no subvencionado por otro que sí lo está, con un impacto nulo en el nivel de empleo, con un coste social sin ninguna consecuencia eficaz y con una desviación del beneficio del objetivo central de creación de empleo ${ }^{98}$.

Por tanto, con las referidas reformas llevadas a cabo, en lo que al régimen de incentivos a la contratación indefinida se refiere, habrá que esperar a la evolución de las mismas para valorar su repercusión sobre el empleo, sobre todo, con relación a los colectivos hacia los que se dirige. Así pues, las expectativas sobre este instrumento no parecen ser muy halagüeñas, especialmente, si tenemos en cuenta que las mismas no parece que hayan dado resultado con anterioridad a la crisis en los colectivos hacia los que se enfoca, si tenemos en cuenta la alta tasa de desempleo con la que cuentan los mismos. Además, creemos que se hace necesario procurar una mayor coordinación entre bonificación y formación, que es lo que de verdad puede garantizar el acceso al mercado laboral y el mantenimiento estable en el mismo, al permitírsele al trabajador con aquella una mejor adaptación a las exigencias y realidades del mercado de trabajo $^{99}$. Sin embargo, parece que la Ley se ha quedado corta en este sentido, puesto que el establecimiento de la formación en el marco de los bonificaciones a la contratación carece de concreción y parece quedarse en una declaración de buenas intenciones.

96 Para calcular dicho incremento se debe acudir a la fórmula establecida en el artículo 10.5 de la ley 35/2010.

97 Ver artículos 10.6 y 10.7 de la ley 35/2010. A este respecto, ver MORALES ORTEGA, José Manuel. Ob. cit., pp. 386-387 y CÁmARA BOTía, Alberto. Ob. cit., pp. 319 y ss.

98 GONZÁlEZ ORTEGA, Santiago. Ob. cit., p. 425.

99 En este sentido, se viene advirtiendo desde las organizaciones internacionales de la necesidad de potenciar en nuestro país las iniciativas de formación dentro de los programas activos del mercado de trabajo. Y es que menos del $25 \%$ del gasto español en estos programas se dedica a la formación, una cifra considerablemente inferior a la de otros países (ver OIT/IIEL. Ob. cit., p. 8).

LA REFORMA

DEL MERCADO

DETRABAJO EN

ESPAÑA DURANTE

LA CRISIS

FINANCIERA

INTERNACIONAL

THE LABOR

MARKET REFORM

IN SPAIN

DURING THE

INTERNATIONAL

FINANCIAL CRISIS 


\section{EL FONDO ESPAÑOL DE CAPITALIZACIÓN INDIVIDUAL: UNA MEDIDA CONTROVERTIDA}

A raíz de la reforma de la ley 35/2010 se prevé en nuestro ordenamiento laboral la creación del denominado Fondo Individual de Capitalización que debiera estar operativo a comienzos de 2012, pero que no ha sido así por las razones que vamos a ver. La ley 35/2010 vino a contemplar en su preámbulo la creación de «un modelo de capitalización individual mantenido a todo lo largo de la vida laboral, por un número de días por año a determinar, para cuya regulación el Gobierno aprobará un Proyecto de Ley. Este Fondo individual de capitalización podrá hacerse efectivo por el trabajador para los casos de despido, así como para completar su formación, en supuestos de movilidad geográfica o, en último término, en el momento de su jubilación. El modelo se dirigirá a dotar a nuestro mercado de trabajo de una mayor estabilidad en el empleo y una más sana movilidad laboral». A tal respecto, la disposición adicional décima de la ley establece, concretamente, que «el Gobierno, en el plazo máximo de un año a partir del 18 de junio de 2010, previa consulta con las organizaciones empresariales y sindicales más representativas, aprobará un proyecto de ley por el que, sin incremento de las cotizaciones empresariales, se regule la constitución de un Fondo de capitalización para los trabajadores, mantenido a lo largo de su vida laboral, por una cantidad equivalente a un número de días de salario por año de servicio a determinar. La regulación reconocerá el derecho del trabajador a hacer efectivo el abono de las cantidades acumuladas a su favor en el Fondo de capitalización en los supuestos de despido, de movilidad geográfica, para el desarrollo de actividades de formación o en el momento de su jubilación. Las indemnizaciones a abonar por el empresario en caso de despido se reducirán en un número de días por año de servicio equivalente al que se determine para la constitución del Fondo. El Fondo deberá estar operativo a partir de 1 de enero de $2012 »^{100}$.

De tal modo, se trataba de poner en marcha en nuestro país un modelo inspirado en el modelo austríaco, aun cuando no deben perderse de vista otras experiencias similares existentes en otros tantos ordenamientos jurídicos, como es el caso de la indemnización por finalización de la relación laboral (trattamento difine rapporto, TFR) del derecho laboral italiano, el más antiguo de todos porque se remonta a la época mussoliniana, o los fondos de cesantía del derecho laboral brasileño, panameño, chileno o colombiano, los cuales también presentan muchos elementos en común con la experiencia austriaca y deben ser tomados en consideración, también, con respecto a la experiencia española. 
No obstante, con relación a la implantación del Fondo Individual de Capitalización en nuestro país, desde la OIT se han venido a realizar diferentes recomendaciones con relación a la aplicación del mismo. En este sentido, se ha venido a afirmar que se debe ampliar el acceso al fondo de capitalización para trabajadores temporales, ya que si el fondo se utiliza únicamente para contratos indefinidos, las empresas podrían verse alentadas a contratar temporalmente, dado el incremento relativo de los costos de contratación. Ampliar el acceso a este fondo a los trabajadores temporales equipararía los incentivos a la contratación en un caso y en otro y tendría la ventaja añadida de promover asimismo la movilidad y la formación de los trabajadores temporales. Ello podría lograrse permitiendo a estos últimos traspasar al fondo el mismo porcentaje del total de la indemnización por despido a que tienen derecho los trabajadores con contratos indefinidos. Además, se ha advertido desde esta Organización que será importante velar por que el fondo no aumente aun más el costo de la contratación, particularmente de los contratos indefinidos. Esto es particularmente pertinente en un momento en que la economía necesita fomentar la competitividad y crear más y mejores puestos de trabajo. El sistema podría evaluarse anualmente a tal efecto. Por último, queremos advertir que se ha venido a resaltar desde dicho organismo que el fondo de capitalización para trabajadores ha de aplicar rigurosas salvaguardias a la hora de invertir a fin de protegerse de las fluctuaciones excesivas, sin renunciar a unos intereses devengados estables ${ }^{101}$.

Debe destacarse también que dicho fondo ha levantado una importante polémica desde que se declarase la intención de instaurarlo a mediados de 2010. En tal sentido, se ha venido argumentando desde los diferentes foros sociolaborales que la implantación del sistema presenta serias dificultades, ya que, por una parte, no parece que vaya a solucionar la actual división que existe entre trabajadores con mucha antigüedad y trabajadores recién incorporados, que ya es bastante acusada en nuestro país. Tal es sin embargo la justificación doctrinal de sus defensores -en España notablemente una fundación neoliberal, la Fundación de Estudios de Economía Aplicada (FEDEA) —, de que suprimiría la distancia entre outsiders e insiders. Además, incrementar los costes fijos de las empresas para poner los fondos en manos de entidades de inversión parece arriesgado en la crisis financiera a la que asistimos en estos momentos ${ }^{102}$. Este último aspecto, vale decir, el incremento de los costes empresariales, es precisamente uno de los extremos que plantea más dificultades con relación al sistema. Si bien al respecto se han venido tratando de aportar posibles vías de solución, como sería el

LA REFORMA

DEL MERCADO

DETRABAJO EN

ESPAÑA DURANTE

LA CRISIS

FINANCIERA

INTERNACIONAL

THE LABOR

MARKET REFORM

IN SPAIN

DURING THE

INTERNATIONAL

FINANCIAL CRISIS 
no incrementar los costes a cargo de las empresas, reduciendo otras cotizaciones distintas de las que financian las contingencias comunes. En dicho ámbito las cotizaciones al desempleo correspondientes a los contratos indefinidos aparecen como la mejor opción de compensación de costes ${ }^{103}$.

En el escenario de dificultades y búsqueda de posibles vías de solución a los problemas que puede presentar la instauración del sistema en nuestro país, surgió un informe elaborado por una Comisión de Expertos en cumplimiento con el mandato establecido en la reforma laboral y el Acuerdo Social y Económico (ASE) como paso previo para articular la norma que regule el fondo, que fue remitido al Ministerio de Trabajo e Inmigración, el cual venía a afirmar que «cualquiera de las fórmulas posibles (para configurarlo) y atendiendo a lo establecido en la ley exigiría un volumen de recursos extraordinariamente elevado»y que «incluso si la economía mejorara sustancialmente», la dificultad para obtener estos recursos «haría prácticamente imposible constituir el Fondo con las características presentes».

Así, el informe concretaba que si se llegara al acuerdo de financiar el fondo de capitalización con ocho días por año, los mismos que costea el Fondo de Garantía Salarial (FOGASA) para sufragar el coste del despido procedente en contratos nuevos, los recursos necesarios a tal fin se elevarían a 7500 millones de euros.

Esta cantidad, especificaba el informe, es equivalente al 1,47\% de la remuneración por asalariado, que incluye, además de la masa salarial, el coste empresarial de la Seguridad Social y el coste por despido; hasta 2,7 puntos de cotización a la Seguridad Social; o el 0,74\% del PBI ${ }^{104}$.

Dicho informe, ante los graves problemas de sostenibilidad económica que advierte con relación a este Fondo Individual de Capitalización, parece haber provocado que el Gobierno desista de su implantación. Aun cuando habrá que esperar una resolución definitiva acerca de esta medida. Las últimas medidas tomadas al respecto se contenían en el real decretoley 10/2011, de 26 de agosto, el cual modificó la regulación contemplada en la ley 35/2010, manifestando las razones en su exposición de motivos: «El grupo de expertos sobre el fondo de capitalización de los trabajadores, constituido conforme a lo pactado en el Acuerdo Social y Económico para el crecimiento, el empleo y las garantías de las pensiones, firmado el 2 de febrero de 2011, constató la falta de viabilidad de esta medida en la actual situación de la economía y del empleo en nuestro país. A la vista de lo anterior, considerando que

103 GómEZ, Valeriano. «¿Es posible trasladar a España el modelo de despido austríaco». Relaciones Laborales, 10 (2010), pp. 1619-1628, p. 140.

104 Consultar alguno de los extractos más destacados de este informe en www.nuevatribuna.es/ artículo. 
se trata de una disposición de la que aún pueden derivarse positivos efectos para la estabilidad laboral, se incluye en este real decreto-ley la prórroga hasta 2013 de la asunción transitoria por el Fondo de Garantía Salarial del resarcimiento a la empresa de una parte de la indemnización en determinados supuestos de extinción del contrato de trabajo».

La iniciativa de constituir un Fondo Individual de Capitalización mantenido a todo lo largo de la vida laboral sigue considerándose acertada y no debe descartarse para el futuro: el nuevo Gobierno conservador surgido de las elecciones de 20 de noviembre de 2011 ha manifestado, por boca de su presidente, el interés en aplicar el modelo austríaco a España, aunque todo parece indicar que tomado en su versión más fuerte, es decir, del «contrato único» a cuya virtud el empresario podría despedir sin causa justificada y con una indemnización proporcional a la antigüedad del trabajador en la empresa. Sin embargo el país tiene suscrito el Convenio OIT 158, de justificación del despido, y la Carta de Derechos Fundamentales de la Unión Europea que entró en vigor en 2009 proclama asimismo el derecho de todo trabajador a ser despedido por causa justificada ${ }^{105}$, lo que dificulta sin duda la posibilidad del despido libre indemnizado. 